This manuscript version is made available under the CC-BY-NC-ND 4.0 1icense

http: //creativecommons.org/licenses/by-nc-nd/4.0/

\title{
An evaluation of environmental plans quality: addressing the rational and communicative perspectives
}

\author{
Constantina Alina $\operatorname{HOSSU}^{1}$, Ioan-Cristian IOJ $\check{A}^{1^{*}}$, Cristina G. MITINCU ${ }^{1}$, Martina \\ ARTMANN $^{2}$, Anna M. HERSPERGER ${ }^{3}$ \\ ${ }^{1}$ University of Bucharest, Centre for Environmental Research and Impact Studies, Bucharest, \\ Romania \\ ${ }^{2}$ Leibniz Institute of Ecological Urban and Regional Development (LG), Germany \\ ${ }^{3}$ Swiss Federal Research Institute WSL, Switzerland
}

Submitted to: Journal of Environmental Management

\begin{abstract}
Environmental action plans are important instruments intended to provide sustainable solutions for the most pressing environmental issues. As they should be updated regularly, efforts to evaluate their quality are essential for enabling incremental improvements in upcoming versions. The aim of our study was to systematically evaluate the quality of Romania's Local Environmental Action Plans (LEAPs) by following a theoretical framework that includes principles from both rational and communicative approaches to assessing plan quality. We selected 32 LEAPs and applied an evaluation protocol that enabled a comprehensive assessment of the plans. Our results showed an overall moderate quality of the LEAPs. Although most plans identify many environmental problems in need of solutions, in reality additional urgent environmental problems often exist. Furthermore, LEAPs perform only moderately in identifying
\end{abstract}


tools for implementation provisions and ensuring the participation of the public in the planning process, and they are even weaker in establishing goals and achieving coordination across different governmental levels. Overall the assessment reveals that plans are rarely able to craft an appealing policy message. Our findings could be used as guidance for LEAP coordinating agencies to improve the plans in the upcoming updating processes, as they identify plan weaknesses and suggest ways to achieve high quality environmental plans. Furthermore, our novel plan assessment method based on rational comprehensive and communicative approaches to plan quality evaluation can be adapted easily to other studies. 


\section{Introduction}

The aim of environmental planning is to achieve sustainability goals by initiating ecological activities to solve critical environmental issues in a way that supports economic development and encourages social empowerment (Davoudi et al., 2019; Zeiger et al., 2019). It has been supported by the international agenda, such as the United Nations conferences on human environment in Stockholm in 1972, on sustainable development in Rio de Janeiro in 2012 or climate change in Paris in 2015 (Bäckstrand and Lövbrand, 2019; Danilov-Danil'yan and Reyf, 2018). Furthermore, dealing with the global challenges brought on by the degradation of the environment through human impacts (i.e., climate change, biodiversity loss) has made many governments worldwide to set commitments to address such challenges. Although improvements have been done (IPPC, 2018), the overall progress is slow due to economic, social, ecological and political factors (Victor et al., 2017). Over the past 46 years, a series of Environmental Action Plans has been supported by the European Environmental Action Programmes (Bourguignon, 2018). Such plans have become important instruments to protect and improve environmental quality by setting environmental priorities while including public participation as an essential part of the process. Furthermore, these plans aim to outline efficient and costeffective solutions to deal with environmental degradation. However, evaluating the quality and implementation of such plans has been difficult due to their comprehensiveness and the amount of time between their making and outcomes occurrence (Ericksen et al., 2017).

Despite the increasing attention to environmental planning in recent years, little is known about the quality of plans dealing with environmental issues overall (Berke and Godschalk, 2009). Recent studies have focused on the evaluation of planning documents from specific policy domains such as: climate change (Woodruff and Regan, 2019), natural hazards (Horney et al., 
2017), housing (Ramsey-Musolf, 2018), ecosystem services (Cortinovis and Geneletti, 2018), green infrastructure (Kim et al., 2018), natural resource management (Potts, 2017), sustainable development (Conroy and Jun, 2016) and forest resources (Fostera et al., 2019).

Evaluation has become an important stage in any planning process, as it provides decision makers with information on whether a plan (i) is achieving its stated goals and policies, (ii) is offering appropriate guidance for its successful implementation and (iii) effectively communicates its intentions (Lyles and Stevens, 2014). Indeed, plan quality evaluation is valuable because it is a "learning process" (Berke and Godschalk, 2009) that aims to bring incremental improvements for upcoming plans. It is difficult to define a "good" plan because plan quality evaluation is subjective, and definitions of success and failure are relative based on the criteria the plans are judged upon. However, some authors suggest that a high quality plan provides "a clear and convincing picture of the future" (Berke and Godschalk, 2009, p. 229), and is persuasive, inspirational, and presents an attractive format easy to read and use (Bunnell and Jepson, 2011). On the other hand, a low quality plan follows a rigid and predetermined structure, is less creative and fails to deliver its promises (Bunnell and Jepson, 2011). The aim of our study was to develop and apply a method to systematically test the quality of Romania's Local Environmental Action Plans (LEAPs). Many plan evaluation studies have been conducted in the U.S. (i.e. Berke et al., 2019; Kim et al., 2018; Spurlock, 2018) and Europe (i.e., Grădinaru and Hersperger, 2018; Mueller and Hersperger, 2015), i.e., in established democracies. Given Romania's nascent democracy and environmental policy shaped by European Union (EU) organizations and conventions, it is a promising study case that can contribute to the international literature. 
In line with discussions in planning theory on the purpose and workings of planning, we can distinguish between different approaches to plan evaluation. In their plan evaluation some authors focus on a rational approach, where plans are seen as blueprints and a logical sequence of principles defining plan quality is assumed. Thus, plans are assessed in terms of the goals they imply and how these are translated into policies whose implementation and monitoring are described to ensure that the problems are addressed (Guyadeen, 2017; Laurian et al., 2010). The rational approach has many flaws, and therefore many studies underlined the importance of assessing the communicative and persuasive power of the plans to supplement the rational model (Bunnell and Jepson, 2011). With this communicative approach, plans are seen as a guide for effective decision making and consensus building and are evaluated in terms of their usefulness (Laurian et al., 2010) and strength (Connell and Daoust-Filiatrault, 2017).

Most existing studies have focused largely on the rational comprehensive dimension and less on the communicative characteristics of the plans (Lyles and Stevens, 2014). A combination of both approaches in plan evaluation would result in a greater understanding of plans' strengths and weaknesses, which may further lead to better and more credible plans (Bunnell and Jepson, 2011; Norton, 2008). Some authors have suggested that the type of evaluation should depend on the purpose of the plan under evaluation and have referred to plans as, for example: visions, blueprints or responses to state planning mandates (Baer, 1997; Hopkins, 2001). However, to date, studies dealing with principles from both rational and communicative approaches in assessing the quality of comprehensive environmental plans are missing. The main goal of our evaluation is to close this gap. We use a framework recently proposed by Connell and DaoustFiliatrault, 2017 but so far, to our knowledge, not operationalized and tested. The novel aspect of our research is thus to operationalize the framework by including in our evaluation core planning 
principles (i.e., goals, fact bases, policies), but also additional principles contributing to plan quality (i.e., public participation, implementation, monitoring, policy focus, organization and presentation) which are under-represented in plan quality research (Guyadeen, 2019) and by testing it with Romanian Environmental Action Plans. Furthermore, our study contributes to planning literature by developing a protocol that can be applied not only to evaluate environmental action plans whose quality has not been examined in other studies but also other plans in different policy domains due to the reliability procedures we employed.

Research protocols and content analysis are the preferred methods to evaluate plan quality. We derived a protocol from the emerging plan quality literature to systematically evaluate the quality of Local Environmental Action plans (LEAPs) in Romania. We hypothesized that the quality of LEAPs is rather similar because they were adopted mostly in the same period and follow the guidance of a handbook for developing LEAPs (Ministry of Environment, 2004).

\subsection{Framework for evaluation}

The framework of Connell and Daoust-Filiatrault (2017) (Figure 1) represents the theoretical basis for our protocol. It is appropriate for our study because it reflects both the rational and communicative approaches to plan quality evaluation. 


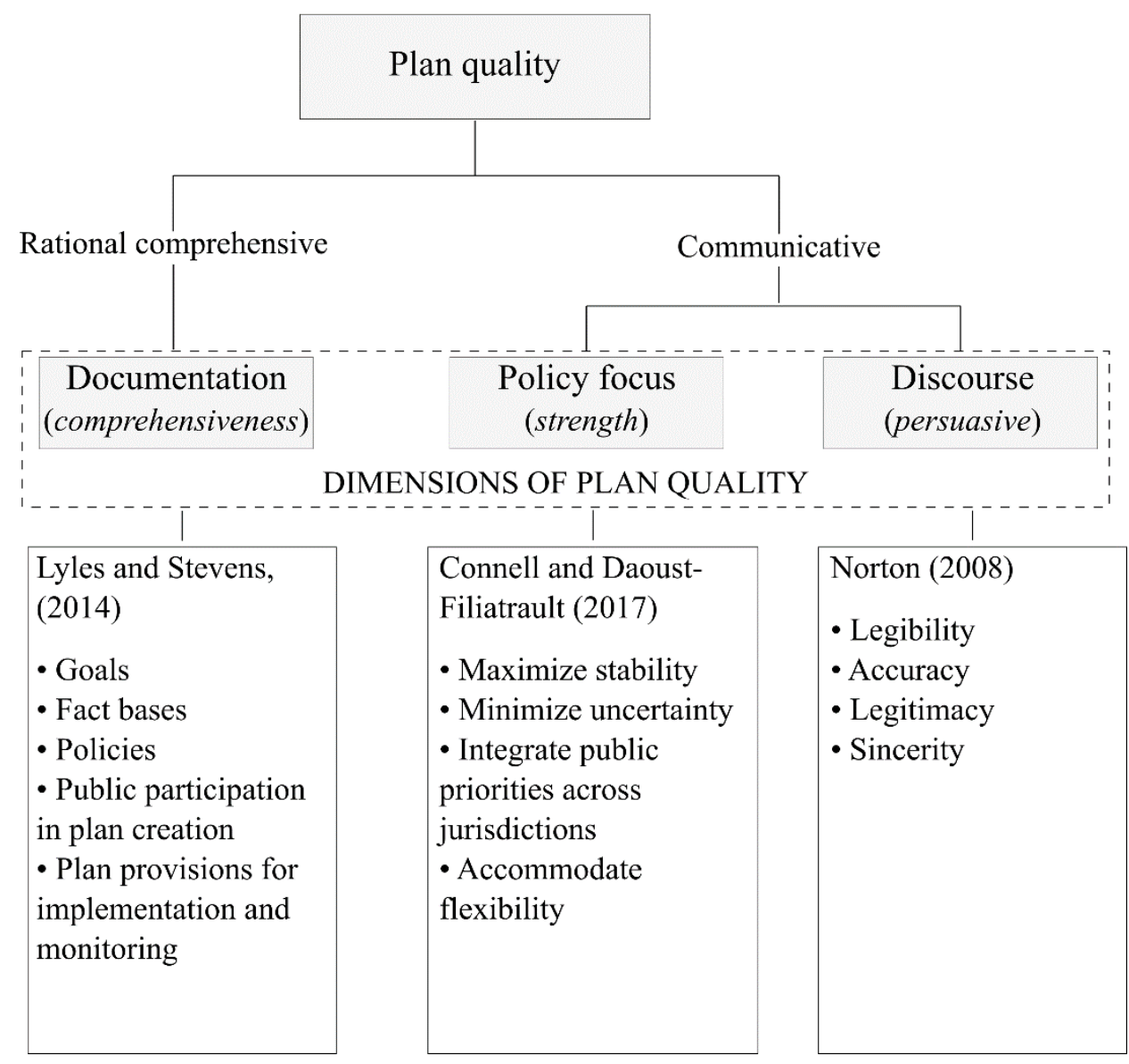

Figure 1: The framework for plan quality evaluation. Source: Connell and Daoust-Filiatrault (2017)

The documentation dimension relates to the plan format and incorporates the core principles according to key studies on plan quality (Table 1). Furthermore, it is important to assess this dimension because research is needed on the range of "goals, policies, types of ecological science-based information and implementation and monitoring actions incorporated into plans" (Berke et al., 2013). The policy focus dimension is important in order to assess a plan's effectiveness as a communicative tool (Norton et al., 2018). It emphasizes the strength of the actions proposed to manage the environmental problems the core focus of the LEAPs. It is more subjective because it relies on researchers' personal judgements when scoring the 
corresponding items. Furthermore, it provides useful information on the consistency between the plan and other policies of hierarchical parties (Table 1). The discourse dimension evaluates a plan's persuasive impact. A high value in the documentation dimension is necessary for a high value in the discourse dimension because most of the items in the discourse dimension relate back to the items in the documentation dimension and even the policy focus dimension (Table 1). The aim of the discourse dimension is to reveal the quality of the plan as a communicative tool overall. Combining these dimensions facilitates a complete assessment of the quality of LEAPs. Table 1: Dimensions and principles used to assess the LEAPs

\begin{tabular}{|c|c|c|}
\hline Dimension/Principle & Definition of the principle & Source of the items \\
\hline \multicolumn{3}{|l|}{ Documentation } \\
\hline $\begin{array}{l}\text { Goals } \\
\text { (direction-setting principle) }\end{array}$ & $\begin{array}{l}\text { Goals are statements of future desired aspirations and } \\
\text { needs, as well as problem alleviations that reflect } \\
\text { shared public concerns. }\end{array}$ & $\begin{array}{l}\text { (Lyles et al., 2014a; Rudolf } \\
\text { and Grădinaru, 2017) }\end{array}$ \\
\hline $\begin{array}{l}\text { Fact Bases } \\
\text { (direction-setting principle) }\end{array}$ & $\begin{array}{l}\text { Fact bases provide descriptive and empirical analyses } \\
\text { of the actual and future local environmental } \\
\text { conditions and impacts (in the absence of planning), } \\
\text { which are further important for the prioritization of } \\
\text { policies. }\end{array}$ & $\begin{array}{l}\text { (Berke and Godschalk, } \\
\text { 2009; Berke et al., 1999; } \\
\text { Rudolf and Grădinaru, } \\
\text { 2017; Stevens, 2013) }\end{array}$ \\
\hline $\begin{array}{l}\text { Policies } \\
\text { (direction-setting principle) }\end{array}$ & $\begin{array}{l}\text { Policies are actions aimed at ensuring that each goal is } \\
\text { achieved and each environmental problem is } \\
\text { alleviated. }\end{array}$ & $\begin{array}{l}\text { (Ministry of Environment, } \\
\text { 2004; Stevens, 2013) }\end{array}$ \\
\hline $\begin{array}{l}\text { Public participation in plan } \\
\text { creation } \\
\text { (action-oriented principle) }\end{array}$ & $\begin{array}{l}\text { A description of the public participation process in the } \\
\text { plan-making process, including identification of the } \\
\text { stakeholders involved, the impact of their input in the } \\
\text { plan's evolution, and the engagement techniques that } \\
\text { were used. }\end{array}$ & $\begin{array}{l}\text { (Rudolf and Grădinaru, } \\
\text { 2017; Steelman and Hess, } \\
\text { 2009; Stevens, 2013) }\end{array}$ \\
\hline $\begin{array}{l}\text { Plan provisions for } \\
\text { implementation and monitoring } \\
\text { (action-oriented principle) }\end{array}$ & $\begin{array}{l}\text { The extent to which organization responsibilities, } \\
\text { timeframes, funds and indicators are assigned for the } \\
\text { policies implementation and monitoring to ensure the } \\
\text { achievement of the stated goals. }\end{array}$ & $\begin{array}{l}\text { (Berke et al., 1999; Rudolf } \\
\text { and Grădinaru, 2017; } \\
\text { Steelman and Hess, 2009; } \\
\text { Stevens, 2013) }\end{array}$ \\
\hline \multicolumn{3}{|l|}{ Policy focus } \\
\hline Maximize stability & $\begin{array}{l}\text { A stable LEAP in terms of policy focus is one that is } \\
\text { based on clear and concise language (including clear } \\
\text { rules and regulations) in the formulation of actions } \\
\text { that can hold up to various challenges and leave little } \\
\text { room for misinterpretation and ambiguity. }\end{array}$ & $\begin{array}{l}\text { (Berke and Godschalk, } \\
\text { 2009; Bunnell and Jepson, } \\
\text { 2011; Connell and Daoust- } \\
\text { Filiatrault, 2017; Norton, }\end{array}$ \\
\hline Minimize uncertainty & $\begin{array}{l}\text { A minimally uncertain LEAP in terms of policy focus } \\
\text { has a good internal coherence (where goals, policies } \\
\text { and implementation are mutually reinforcing), clearly }\end{array}$ & $\begin{array}{l}\text { 2008; Rudolf and } \\
\text { Grădinaru, 2017) }\end{array}$ \\
\hline
\end{tabular}




$\begin{array}{ll} & \begin{array}{l}\text { defining responsibilities for action implementation } \\ \text { and monitoring. }\end{array} \\ \text { Integrate public priorities } & \begin{array}{l}\text { This principle aims to ensure consistency of the LEAP } \\ \text { with other plans and policies at different } \\ \text { governmental levels. }\end{array} \\ \text { Accommodate flexibility } & \begin{array}{l}\text { A flexible LEAP avoids presenting a highly rigid } \\ \text { framework by including possible exceptions to }\end{array} \\ & \text { general rules in the formulation of actions and } \\ & \text { governance mechanisms. } \\ \text { Discourse } & \begin{array}{l}\text { A legible LEAP includes clear and complete } \\ \text { information on the plan's internal (specifically }\end{array} \\ & \text { regarding goals, policies and associated } \\ \text { implementation responsibilities) and external quality } & \text { (specifically regarding the way it is organized). } \\ \text { An accurate LEAP is solid in terms of the fact bases } \\ \text { analyses. } \\ \text { The legitimacy of a LEAP is enhanced when the plan } \\ \text { is legible and public participation is used. } \\ \text { A sincere LEAP minimizes uncertainty, builds } \\ \text { cohesion across jurisdictions and communicates the } \\ \text { implementation plan and outcomes. }\end{array}$

\subsection{Environmental policy in Romania}

Romanian environmental policy development has been intertwined with the process of Romania's integration into the European Union (EU) in 2007. Environmental protection began in 1973 with the first Law on Environmental Protection, whereas today the environmental protection legislation is strongly determined by the EU legislation (Petrescu-Mag, 2008). In Romania, the foremost governmental institutions on environmental matters are the Ministry of the Environment, which coordinates the National Environmental Protection Agency (NEPA), and Romania's National Environmental Guard. All of Romania's 42 counties have an Environmental Protection Agency (EPA) to whom the NEPA delegates the responsibility of implementing environmental policies. The principal instruments for environmental policy are Environmental Action Plans (EAPs). Such plans identify the most pressing environmental problems, establish objectives, targets, timetables, and actions required to achieve the 
management of the environmental problems, and describe tools for their implementation and monitoring. During the pre-accession to the EU, Romanian governmental bodies began to draft EAPs on the national, regional and local (county) levels. Today, there is one national EAP and 42 local EAPs (LEAPs).

Our study focuses on the evaluation of the Romanian LEAPs. The guidance material for developing the plans is provided in a handbook (Ministry of Environment, 2004) that is based on a guide prepared by Markowitz (2002) and the methodology established within a project (PHARE Project RO 9804.04.01.001, 2001). LEAPs are not binding but are intended to provide guidance to help mitigate the most urgent environmental problems. They are required to include participatory approaches to ensure the effective implementation of the environmental protection actions. Their drafting involves a range of experts, from public agencies to private companies and NGOs, and their approval, implementation and monitoring are the responsibility of different institutions (Figure 2). Regular updating (every three or five years) and monitoring are required for the LEAPs (Ministry of Environment, 2004). LEAP monitoring is a voluntary and nonbinding process that aims to provide information about the implementation status of the actions based on the reports of the institutions that took responsibility for action implementation. Often, a wide range of actions are not implemented in a timely and effective manner (Vasile and Holt, 2014). 


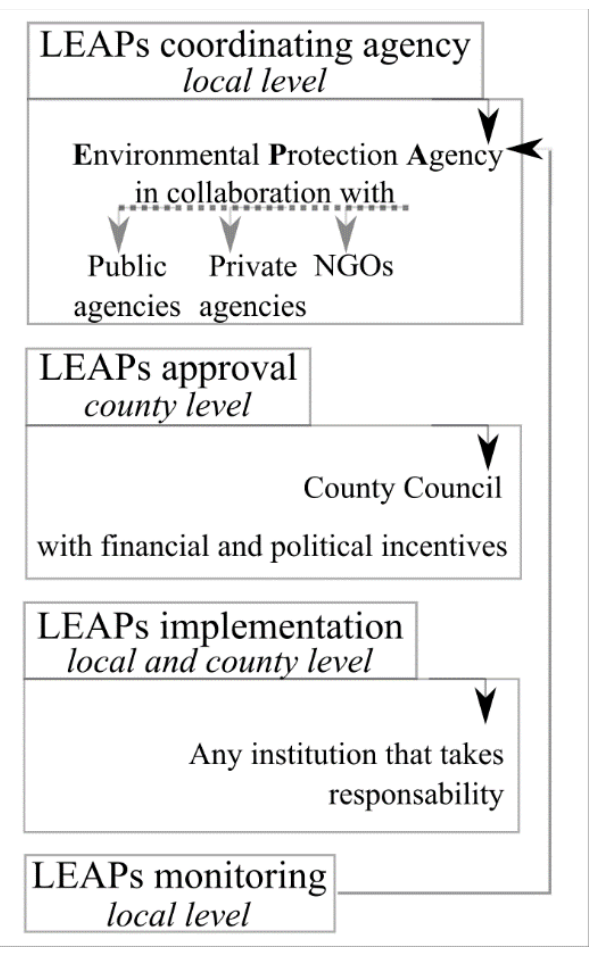

Figure 2: Local Environmental Action Plans (LEAPs) cycle and responsible institutions (authors' own compilation)

\section{Material and Methods}

\subsection{Study area}

The target sample consists of Romanian counties that have a LEAP (Figure 3). Bucharest (Romania's capital city) was excluded from the potential sample of 42 because it is a city state and differs from the other counties in several dimensions such as population size, urbanization and environmental conditions. In order to ensure that all the items of the protocol could be assessed, the sample was further limited to those counties with a complete LEAP containing all the main sections: (i) initiation, organization and institutionalization of the planning process; (ii) county's current and projected environmental quality; (iii) identification and prioritization of county's environmental problems; (iv) local action plan to deal with the identified environmental 
problems; (v) implementation of the action plan; (vi) monitoring of the action plan; and (vii) evaluation of the outcomes and plan update (Ministry of Environment, 2004). Furthermore, we could not obtain the LEAPs from two counties, owing to administrative burdens.

The protocol was pretested on four LEAPs that were not included in the final sample. Thus, out of 42 counties total, the final sample included 32 counties along with their LEAPs, covering $193,758 \mathrm{~km}^{2}$ ( $81.28 \%$ of Romania's total area), with $13,682,092$ inhabitants ( $61.52 \%$ of Romania's total population) (NIS, 2017). The sample thus included counties from all eight of Romania's development regions, from sparsely to densely populated counties (range $=29.2 \neg$ 150.8 inhabitants $/ \mathrm{km}^{2}$ ), as previous studies have shown that population size has a positive influence on plan quality (Berke et al., 1999; Stevens, 2013; Tang and Brody, 2009) and counties with a large population may produce higher quality plans.

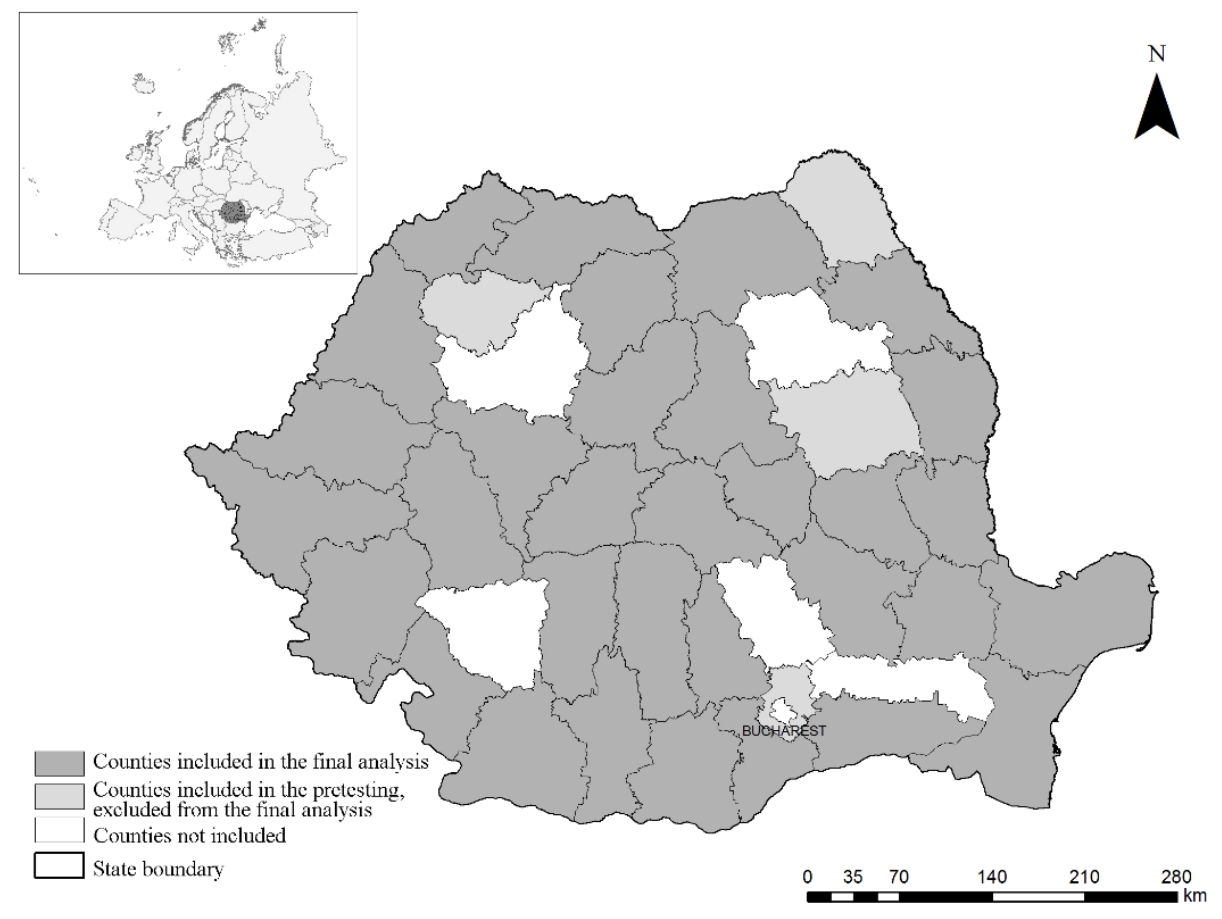

Figure 3: Distribution of the sampled counties. The location of Romania within Europe is given in the inset. Source: geo-spatial.org; Map: Mitincu, (2019) 


\subsection{Data collection}

The LEAPs were collected (i) from the websites of each county's EPA and (ii) if necessary, by e-mail request. All plans are the current approved versions, with the most recent changes implemented (Table 2).

Table 2: Counties and LEAP characteristics

\begin{tabular}{|c|c|c|c|c|}
\hline $\begin{array}{l}\text { County (final } \\
\text { analysis) } \\
\text { County } \\
\text { (pretesting) }\end{array}$ & $\begin{array}{l}\text { Population } \\
\text { (NIS, 2017) }\end{array}$ & $\begin{array}{l}\text { Year of } \\
\text { plan's } \\
\text { initial } \\
\text { adoption }\end{array}$ & Analyzed version & Current status at the time of analysis \\
\hline Alba & 330973 & 2004 & 2006 (first revision) & $\begin{array}{l}\text { second revision initiated in } 2013, \\
\text { not finished }\end{array}$ \\
\hline Arad & 422029 & 2005 & 2009 (first revision) & second revision scheduled for 2013 \\
\hline Argeș & 590561 & 2004 & 2009 (second revision) & third revision scheduled for 2013 \\
\hline Bacău & 595654 & 2005 & 2014 (first revision) & no other initiated \\
\hline Bihor & 566435 & 2004 & 2016 (second revision) & no other initiated \\
\hline Bistrița-Năsăud & 281432 & 2004 & 2015 (second revision) & no other initiated \\
\hline Botoșani & 390404 & 2006 & 2013 (second revision) & third revision scheduled for 2017 \\
\hline Braşov & 550747 & 2005 & 2011 (second revision) & $\begin{array}{l}\text { third revision initiated in } 2015 \text {, not } \\
\text { finished }\end{array}$ \\
\hline Brăila & 299125 & 2006 & 2010 (first revision) & $\begin{array}{l}\text { second revision initiated in } 2013 \text {, } \\
\text { not finished }\end{array}$ \\
\hline Buzău & 425856 & 2005 & 2013 (first revision) & no other initiated \\
\hline Caraş-Severin & 279119 & 2004 & 2007 (first revision) & $\begin{array}{l}\text { second revision initiated in } 2014 \text {, } \\
\text { not finished }\end{array}$ \\
\hline Călărași & 292843 & 2004 & 2006 (first revision) & no other initiated \\
\hline Constanța & 678406 & 2005 & 2005 (first revision) & $\begin{array}{l}\text { last revision initiated in } 2012 \text {, not } \\
\text { finished }\end{array}$ \\
\hline Covasna & 204958 & 2004 & 2011 (second revision) & no other initiated \\
\hline Dâmbovița & 501302 & 2004 & 2013 (second revision) & third revision scheduled for 2017 \\
\hline Dolj & 635589 & 2004 & 2016 (third revision) & no other initiated \\
\hline Galați & 514429 & 2006 & 2010 (second revision) & $\begin{array}{l}\text { third revision initiated in } 2016 \text {, not } \\
\text { finished }\end{array}$ \\
\hline Giurgiu & 274050 & 2003 & 2016 (fourth revision) & no other initiated \\
\hline Harghita & 305709 & 2003 & 2013 (second revision) & no other initiated \\
\hline Hunedoara & 393154 & 2002 & 2012 (second revision) & no other initiated \\
\hline Iași & 789977 & 2004 & 2014 (second revision) & no other initiated \\
\hline Ilfov & 460517 & 2005 & 2012 (second revision) & no other initiated \\
\hline Maramureș & 465487 & 2001 & 2013 (third revision) & no other initiated \\
\hline Mehedinți & 249459 & 2011 & 2015 (third revision) & no other initiated \\
\hline Mureș & 540790 & 2004 & 2007 (first revision) & second revision finished in 2017 \\
\hline Olt & 407741 & 2004 & 2016 (second revision) & no other initiated \\
\hline Satu-Mare & 336562 & 2004 & 2014 (second revision) & no other initiated \\
\hline
\end{tabular}




\begin{tabular}{lllll} 
Sălaj & 215910 & 2004 & 2007 (first revision) & no other initiated \\
Sibiu & 399758 & 2004 & 2014 (second revision) & no other initiated \\
Suceava & 627934 & 2005 & 2014 (second revision) & no other initiated \\
Teleorman & 349688 & 2004 & 2014 (second revision) & no other initiated \\
second revision initiated in 2011, \\
Timiş & 698201 & 2008 & 2008 (first revision) & not finished \\
& & & & no other initiated \\
Tulcea & 200716 & 2005 & 2011 (second revision) & no other initiated \\
Vaslui & 384144 & 2005 & 2012 (second revision) & no other initiated \\
Vâlcea & 356716 & 2016 & 2016 (third revision) & no other initiated \\
Vrancea & 328202 & 2006 & 2012 (second revision) & \\
\hline
\end{tabular}

\subsection{Coding protocol and content analysis of Local Environmental Action Plans}

\section{(LEAPs)}

An evaluation protocol consisting of 89 items, grouped into 13 categories and 3 dimensions, was used to systematically evaluate the quality of LEAPs (Appendix 1). The protocol covers the entire plan content. Most items are used to assess the first dimension, documentation, because of the many environmental fields and many provisions for implementation and monitoring. Fewer items are used when assessing the policy focus and discourse characteristics because they represent a summary evaluation of the LEAPs or of the items from the documentation dimension.

Most available research protocols include core principles of plan quality that can be applied to plans from a wide range of domains and scales (Berke and Godschalk, 2009). It is important that a protocol builds upon the existing ones in order to contribute to the body of knowledge on plan quality (Stevens et al., 2014). Therefore, the items of the protocol were developed on the basis of previous studies in the literature of plan quality (Table 1) and a handbook for developing LEAPs (Ministry of Environment, 2004) when dividing the policies principle into four representative categories: (i) management of natural resources; (ii) 
environmental nuisances; (iii) institutional and administrative capacity; and (iv) environmental education awareness, public health and recreation.

The scoring method that we applied to evaluate the LEAPs followed a binary and threelevel ordinal scale (Berke and Godschalk, 2009). For the binary scale, 0 means the item in question is not included, while 1 means the item is included in the LEAP. For the ordinal scale, 0 means the item in question is not present; 1 means there is a general description of the item in question or a partial illustration of the item; and 2 means that there is a detailed description of the item in question or a more complete illustration of the item, measured as: (i) "none", "some" and "most"; (ii) "never", "seldom" and "often"; and (iii) "poor", "middle" and "high".

The protocol was imported into a content analysis software program (MAXQDA 18.1.0, VERBI Software GmbH, Berlin, Germany) to improve efficiency and reliability in coding procedures. To produce reliable and replicable data, specific conditions have to be met and standard content analysis procedures have to be employed (i.e., use multiple coders who work independently; employ an adequate intercoder reliability measure; report reliability scores for each quality item of the plan) (Berke and Godschalk, 2009; Krippendorff, 2013; Lyles et al., 2014b; Lyles and Stevens, 2014).

The content analysis of the LEAPs followed standard coding procedures (Krippendorff, 2013). A training process was carried out where instructions on the protocol items were presented to the two coders so that the items could be consistently evaluated. Two coders applied the protocol in a pretesting process on four LEAPs. After the pretesting process and the subsequent analysis of the four plans, the protocol was refined. The two coders content analyzed all plans independently of each other. When disagreements in scores between the two coders were identified (see below), the coders reassessed the plan documents and engaged in discussion 
to arrive at a consensus on which coder's score should be assigned to each item for which there was disagreement.

A standardized index score was computed for each protocol category, in line with previous plan quality studies (Berke and Godschalk, 2009; Lyles et al., 2014a). First, the ordinal items were divided by 2.0 to place them on a $0.0-1.0$ scale. According to Lyles et al., (2014), this procedure ensures equal weighting of binary and ordinal items. Second, the scores for all items within an individual category were summed. Third, the summed scores were divided by the total number of items per category. Last, the generated score was multiplied by 10 to place each category on a scale of $0.0 \neg 10.0$. We considered plans/principles/dimensions with a score of 0.0 $\neg 4.0$ as having a low quality, $4.0 \neg 7.0$ as having a moderate quality, $7.0 \neg 9.0$ as having a high quality and $9.0 \neg 10.0$ as having a very high quality.

Coding reliability was determined by calculating Krippendorff's alpha (Krippendorff, 2013) for the results of both the pretesting process and the final analysis. Such a measure of agreement between the coders is neglected in many planning evaluation studies (Stevens et al., 2014), but it is important for producing reliable and transparent plan quality data. For each item in the protocol, the alpha value was calculated using the "kripp.alpha" function in the irr package in the statistical software R (R Core Team, 2017) (Appendix 1). We followed the standards recommended by Stevens et al. (2014) to decide which items were reliable and should thus be included in the final analysis. Therefore, the 13 categories were classified depending on (i) the number of items each category included and (ii) the degree to which the items were distributed throughout the plans. Four categories of items emerged (Table 3).

Table 3: Standards for the interpretation of Krippendorff's alpha (adapted from Stevens et al., 2014)

\begin{tabular}{lll}
\hline Plan quality categories & $\begin{array}{l}\text { Upper } \\
\text { standard }\end{array}$ & $\begin{array}{l}\text { Lower } \\
\text { standard }\end{array}$ \\
\hline
\end{tabular}




\begin{tabular}{lcc}
$\begin{array}{l}\text { 1. Few items, highly discrete (Goals; Maximize Stability, Minimize } \\
\text { uncertainty, Accommodate Flexibility; Accuracy, Legitimacy, }\end{array}$ & 0.80 & 0.67 \\
$\begin{array}{l}\text { Sincerity) } \\
\begin{array}{l}\text { 2. Many items, highly discrete (Fact bases; Policies; Plan provisions } \\
\text { for implementation and monitoring) }\end{array}\end{array}$ & 0.70 & 0.58 \\
$\begin{array}{l}\text { 3. Few items, highly distributed (Public participation in plan creation; } \\
\text { Integrate public priorities across jurisdictions) }\end{array}$ & 0.50 & 0.42 \\
\begin{tabular}{l} 
4. Many items, highly distributed (Legibility) \\
\hline
\end{tabular} & 0.40 & 0.33 \\
\hline
\end{tabular}

Items with alpha scores between the upper and lower standards were reassessed and reconciled. Items above the upper standards were only reconciled (Appendix 1). In the pretesting process there were three items with alpha scores below the lower standards and five items between the upper and lower standards. As the items with scores below the lower standards were considered important for the study, the differences between the two coders were reconciled based on a reassessment of the protocol.

In the final analysis, robust results were achieved, as $97 \%$ of the protocol items had alpha scores above the upper standards and only three items had alpha scores between the upper and lower standards.

Furthermore, there were some items that lacked variability in the codes, and the values of Krippendorff's alpha that emerged were misleadingly low. For such items, we calculated the percent agreement, as recommended by Stevens et al. (2014). In the final analysis the percentagreement scores for these items ranged from $94 \%$ to $97 \%$. Other authors suggest that a percentagreement score of at least $80 \%$ is considered acceptable (Berke and Godschalk, 2009).

Mean plan quality scores and their standard deviations were calculated for all 13 categories of plan quality. There were cases where most of the plans had the same high score (i.e., 10) for a given category while a few had the same low score (i.e., 0). In such cases, the standard deviation was quite high (i.e., Goals, Accuracy) despite the low variation. We thus also 
calculated the mode for each item and displayed the value with the highest frequency (Appendix 1).

\section{Results}

The overall mean score of all three dimensions was 6.53 (6.54 for documentation, 6.31 for policy focus and 6.73 for discourse), which indicates a moderate score out of a possible score of 10. The mean scores and standard deviations are presented in Figure 4 for the 13 categories of plan quality for the overall sample of 32 counties (for detailed values see Appendix 2). In the following sections we describe (i) the main plan quality findings for the dimensions and principles and (ii) a comparison of the scores for the individual plans. 


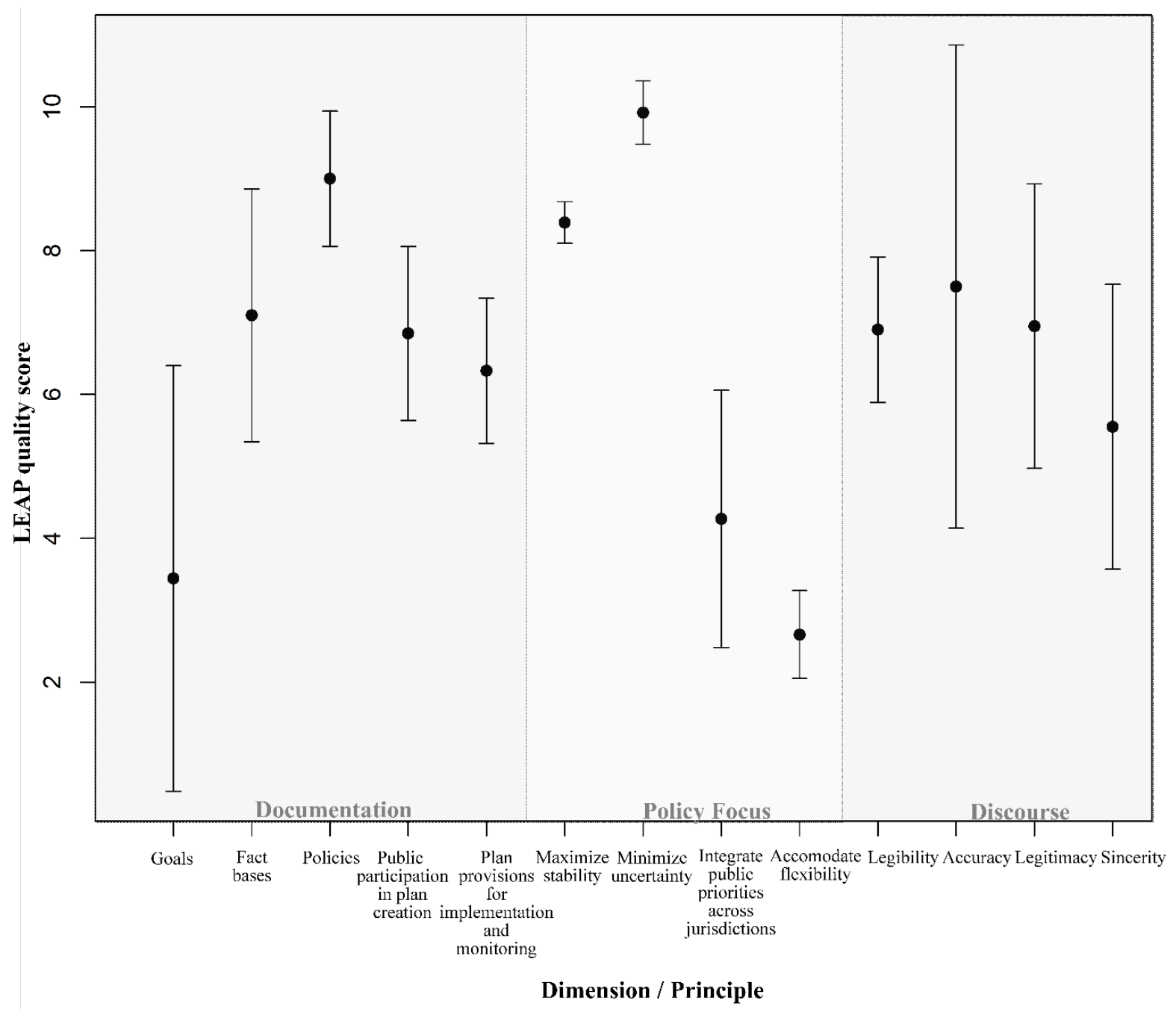

Figure 4: Mean and standard deviation of Local Environmental Action Plan quality scores

\subsection{Quality of dimensions and principles}

The analysis of the principles from the documentation dimension indicates high variability in the scores for the three direction-setting principles, ranging from 3.44 for goals to 7.10 for fact bases and 9.00 for policies, while the scores for the two action-oriented principles are quite similar, ranging from 6.33 for implementation and monitoring provisions to 6.85 for public participation in plan creation. Slightly over half of the plans (56\%) include all principles defining plan quality. 
Low scores for goals result from broadly formulated goals at the beginning of the plan document. Furthermore, the plans often only present goals that are required by the regulations. All plans have a rather strong fact base, resulting from (i) the quality of the illustrations used to depict the environmental quality indicators and (ii) the reliance on multiple data sources. Indeed, all LEAPs have tables (100\%), 91\% had diagrams, $69 \%$ had maps and 53\% had other illustrations (i.e., pictures). The most common data sources were official statistics, specifically the Counties' Annual Environmental State Reports (in 94\% of the plans) These reports contain detailed and locally specific analyses of environmental quality based on long-term monitoring.

The relatively strong fact bases is most likely the result of the plan-format requirements issued by the national government, which indicate that a section discussing the current local environmental conditions and pressures must be included. The high values for policies indicate that the LEAPs demonstrate a proactive stance in the mitigation of a wide range of environmental problems. The most prevalent policies are those related to the management and protection of air, water, soil and wildlife, while policies related to the management of consumptive activities (i.e., hunting, fishing and timber harvesting) and to the improvement of public health are least common.

The scores for both action-oriented principles are moderate. Most of the plans were written with the involvement of public officials, private companies and NGOs (in $78 \%$ of the LEAPs), while a solid engagement of citizens and mass-media was rare. The most common participation techniques used were stakeholders' meetings (in 50\% of the LEAPs), surveys (44\%), and expert opinion and participation incentives, i.e., posting information related to the LEAP on the Internet (each in $34 \%$ of the LEAPs), while public debates (9\%) and consensus negotiations $(16 \%)$ were least common. 
Almost all the analyzed LEAPs include detailed provisions regarding assigning responsibilities to specific actors for implementing actions, establishing timelines and targets for actions, and finding funding sources for the implementation of actions ( $88 \%$ of LEAPs have scores higher than 7.5 for implementation provisions). However, some of them lack a detailed section on monitoring, i.e., the identification of responsible actors, timelines or methods for updating the plans. Indeed, only $9 \%$ of the LEAPs score higher than 7.5 for monitoring provisions.

Within the policy focus dimension, the principles' mean scores vary widely: 8.39 for maximize stability, 9.92 for minimize uncertainty, 4.27 for integrate public priorities across jurisdictions, and 2.66 for accommodate flexibility. LEAPs are highly stable and minimize uncertainty by using clear language in the formulation of actions, establishing enforceable mechanisms, and showing good consistency between actions. On the other hand, the plans are quite rigid and lack flexibility regarding overriding governance mechanisms such as citizen participation, working groups or possible exceptions to the general regulations in the formulation of actions.

The principles from the discourse dimension reveal moderate and high scores: 6.90 for legibility, 7.50 for accuracy, 6.95 for legitimacy and 5.55 for sincerity.

The almost high score for legibility can be attributed to the fact that LEAPs follow a predetermined structure, as outlined in the handbook for developing LEAPs (Ministry of Environment, 2004), and therefore are highly standardized, and also to the high scores for policies and moderate scores for implementation and monitoring provisions. The high score for accuracy is rooted in the plans' strong descriptive and analytical fact bases. Regarding legitimacy, the LEAPs score relatively high for legibility but lower in public participation. The 
moderate score for sincerity is due to the moderate scores in implementation and monitoring provisions, the high scores in minimizing uncertainty, and the low scores in integrating public priorities across jurisdictions and in providing a section that communicates how many actions have been implemented.

\subsection{Comparison of individual plans}

Overall, the LEAP of the County of Giurgiu has the highest score (7.68), whereas the County of Mureș has the lowest score (5.15). Less than half of the counties (31\%) have scores over 7.0, indicating a high quality of their LEAPs, while the remaining counties $(69 \%)$ have scores between 5.0 and 7.0, indicating moderate quality of their plans.

In terms of the documentation dimension, Satu Mare's LEAP has the highest score (7.97, indicating high quality of the plan), while Hunedoara's LEAP has the lowest score (4.94, indicating moderate quality of the plan) (Appendix 2). The difference between these two counties is caused by differences in the quality of goals, fact bases and policies. For example, Satu Mare's LEAP offers clear goals in the beginning of the document, supporting the definition of problems, needs and aspirations in terms of environmental quality that have to be alleviated or understood, and strong fact bases, providing clear visual information and data sources that enhance the selection of priority environmental problems. In contrast, Hunedoara's LEAP fails to identify any clear goals and provides limited fact bases in terms of visual information and data sources.

Regarding the policy focus dimension, Giurgiu's LEAP has the highest score (7.29, indicating high quality of the plan), while Mureș's LEAP has the lowest score (5.21, indicating moderate quality of the plan). The difference between them is the result of a discrepancy in the degree of coordination between the plans and other planning documents of hierarchical parties. 
For example, Giurgiu's LEAP entails vertical, horizontal and intercommunal coordination with other planning documents of federal, regional and local parties, such as coordination with the policies and strategies of the Ministry of the Environment, the Agency for Regional Development and local EPAs, to successfully implement the proposed environmental actions. In contrast, Mureș's LEAP does not specify how the plan coordinates with hierarchical parties. Giurgiu's LEAP represents the fourth revision of the plan, while Mureș's LEAP is the first revision.

In terms of the discourse dimension, Sibiu's LEAP has the highest score (8.61, indicating high quality of the plan) while Buzau's LEAP has the lowest score (3.55, indicating low quality of the plan). For example, Sibiu's LEAP is well organized in terms of content and structure, it addresses coordination with other plans and policies at different levels, and it communicates the results of the monitoring activities. In contrast, Buzau's LEAP fails to achieve in all these aspects and provides a very low quality section on fact bases, with poorly written text and no visual information regarding the environmental problems characterizing the county.

\section{Discussion}

The overall mean scores indicate a moderate quality of the LEAPs and stresses the need for plan improvement. However, previous research has also found a moderate quality of local hazard mitigation plans (Berke et al., 2012; Lyles et al., 2014b), local comprehensive plans (Kim et al., 2018), environmental impact reports (Tang et al., 2008) and national adaptation plans (Woodruff and Regan, 2019). The systematic evaluation of the 32 LEAPs with the detailed protocol revealed the plans' specific strengths and weaknesses and can serve as a starting point for discussing necessary improvements. 
One might assume that plan quality is higher in plans that have undergone several updates, as they are more likely to include incremental improvements. Although some studies have demonstrated that outdated plans can have low plan quality scores (Kim et al., 2018; Tang and Brody, 2009), we did not find a relationship between the plan quality overall and reviews (comparing first edition plans and plans that had been revised ( $\mathrm{t}$-test $=1.959, \mathrm{p}>0.05$ ). Our results correspond to those reported by Potts (2017) regarding natural resource management plans in two states in Australia.

\subsection{Quality of documentation}

Since the documentation of policies principle has the highest middle score out of all principles, we can expect that LEAPs bring into focus the most pressing environmental problems. Indeed, clear goals are important for the effective formulation and implementation of actions and policies (Tang, 2008), while accurate fact bases offer a basis for strong policies (Berke et al., 2013). However, urgent problems, such as those related to climate change and deforestation, are not among the prominent ones even though significant related events have affected many counties across the country (Petrişor, 2015; Purica, 2015). This suggests a poor representation of the real problems by the LEAPs, possibly because the plans mostly rely on official statistics when they establish the environmental problems that require attention. However, it has been shown that the data sources used for producing statistics regarding green spaces in Romania do not produce correct and reliable results (Badiu et al., 2016). Furthermore, LEAPs are developed through collaborative efforts without any financial aid from the government, which could explain why the plans rely on the existing official statistics and miss the real environmental problems. High-quality plans must be well grounded in local 
environmental problems because an environmental problem that is not described in a LEAP will not be politically acceptable and economically feasible to address.

The moderate scores for public participation and implementation and monitoring raise concerns about the potential for successful implementation of LEAPs. LEAPs are written based on the input of multi-agency committees. Although other studies have found a higher participation value when such multi-agency committees are involved (i.e., Woodruff and Regan, 2019), our study shows the opposite pattern. This might be because the young democracy in Romania means that its national planning system suffers from limited experience with participatory processes (Puscasu, 2009). Even though procedural pathways are presented to citizens, their engagement in the LEAP-making process is very low. People have low trust in institutions and public authorities because they perceive that they have no power to influence the decision-making process (Baba et al., 2009). Furthermore, consensus is very rarely mentioned as a participation technique used in the LEAPs, even though it is considered among the best methods available for public participation (Susskind and Cruikshank, 2006). This is because collaborative processes are poorly run in Romania and usually fail to produce longer-term outcomes (Hossu et al., 2018, 2017). Other studies have likewise found a moderate quality of participation processes when evaluating the quality of local mitigation plans (Lyles et al., 2012). Moderate implementation and monitoring scores indicate a modest ability of plans to effectively deal with the environmental problems through the proposed actions, and they suggest poor efforts in checking whether the process is meeting the predetermined benchmarks. This can result from sharing responsibility for LEAP implementation and monitoring across too many parties (Figure 1), which may delay the implementation and monitoring of proposed actions. Furthermore, LEAPs usually lack information about the costs of implementation. Most LEAPs 
specify that such costs are difficult to estimate. However, these details are important for subsequent steps (Hossu et al., 2018).

\subsection{Policy strength}

The poor coordination of the LEAPs with other planning documents of hierarchical parties (for the moderate quality plans) can be explained by the fact that numerous aspects of environmental policy are also coordinated by other ministries, and in Romania the level of coordination between institutions on environmental matters is low (Hossu et al., 2018; Nita et al., 2016). Furthermore, Horney et al. $(2017,2012)$ explained that coordination across different levels may be hampered when plans refer to urban areas where several actors should work in coordination and a history of collaboration barely exists.

The high scores for stability and minimizing uncertainty characterize the proposed LEAP actions as highly knowledgeable of the environmental problems they intend to address. Stable and certain actions represent a strong base that can be used to achieve effective environmental protection, as they leave little room for misinterpretation. However, being too stable or too strict may bring failure regarding effectiveness in certain circumstances. For instance, flexible responses for sustainable land use planning are crucial to adapt to local circumstances and temporal dynamics (Artmann, 2014; Oskam and Feng, 2008). Furthermore, in the LEAPs each action is accompanied by a definition of the problem that requires action, general and specific goals, indicators and targets, thereby reducing possible misinterpretation or confusion regarding the actions.

The low scores for the flexibility principle indicate the difficulty of the actions in being adaptable to special circumstances. Governance mechanisms and possible exceptions to the environmental and planning regulations, as measures of flexibility (Connell and Daoust- 
Filiatrault, 2017), are poorly addressed in the formulation of LEAP actions. This can make the implementation of actions harder, as confirmed by reports from the environmental protection agencies on the status of LEAP action implementation (NEPA, 2016). Furthermore, in Romania

local participatory governance in environmental matters rarely takes place, in order to ensure efficient conservation activities (Manolache et al., 2018). As any plan is bound to be imperfect, it is important to recognize the future value of engaging stakeholders. This will make future planning more likely to succeed as stakeholders learn how to perfect the process.

\subsection{Discursive potential and recommendations to improve the quality of Romanian \\ LEAPs}

The evaluation of the LEAPs as a communicative tool using the principles from the discourse dimension reveals specific aspects that need to be improved to enhance LEAP quality. Specifically, there is a need to improve: (i) LEAP legitimacy by improving public involvement in the planning process, creating opportunities for feedback and integrating the feedback back into the plans. Furthermore, LEAP coordinating agencies should involve research experts in LEAP development in order to benefit from their expertise and identify the most relevant and urgent environmental issues to be solved; (ii) LEAP legibility by defining clear goals in the beginning of the document to serve as solid benchmarks for action formulation, and by providing clear implementation and monitoring guidance to ensure that the proposed actions have the desired effects (Tang, 2008); and (iii) LEAP sincerity by improving inter-level consistency and communication of action progress to advance toward a successful implementation of plans (Stevens, 2013). 
LEAP coordinating agencies may take advantage of the protocol and results described in this study. Doing so will help them understand the main weaknesses of the plans and react accordingly by developing high quality LEAPs in the next updated versions.

\subsection{Conclusions}

The aim of our study was to systematically evaluate the quality of Romania's Local Environmental Action Plans (LEAPs) by operationalizing and testing a theoretical framework (i.e., Connell and Daoust-Filiatrault 2017). We properly achieved this aim by developing a comprehensive evaluation protocol consisting of 89 items that include principles from both rational and communicative approaches to assessing plan quality. By employing standard content analysis procedures, we produced reliable data (as indicated by the high reliability scores for most of the protocol items, Appendix 1) about the quality of local environmental action plans in Romania. Furthermore, the combination of the rational and communicative approaches proved to be helpful. Our evaluation and the associated protocol thus focused on how well the plans conform to specific characteristics (the rational approach), coordination and governance issues, as well as the strength of the plans in improving public and private decision making regarding environmental quality.

In many counties, the handbook for developing LEAPs (Ministry of Environment, 2004) played an important role during the writing up of the LEAP. The handbook provides, for example, lists of environmental problems the plans should/could address and actions that could be taken. In the protocol, the policy focus dimension can be directly linked to the handbook because the four categories and their associated items were selected based on the handbook. However, during plan assessment we encountered other relevant environmental issues, such as restoration of artistic works, preservation of historical and archaeological sites and improvement 
of knowledge regarding environmental legislation, and the list had to be amended accordingly. Such issues are of particular importance, for example heritage and culture resources are in urgent need to be wisely and collaboratively managed and protected for the benefit of cities dwellers and future generations (Verdini et al., 2016).

Our protocol included many items, and it might be difficult for other researchers to address all of them when there are not enough resources or when the purpose of evaluation differs. Further research should address plan conformance, i.e., the implementation of policies as stated in the LEAPs (as a reflection of the rational approach), and plan performance, i.e., the use of the plan in decision making (as a reflection of the communicative approach). This could be done, for example, with personal interviews and case-study analysis. Such an analysis could also be used to reveal the factors that support and impede high plan quality. Future research on the consistency of LEAP policies with recent concepts, such as nature-based solutions or ecosystem services, could be helpful to develop effective environmental policies. In fact, concepts such as ecosystem services can support comprehensive environmental planning approaches in systematically developing goals, analyzing its status and assessing planning impacts on environmental qualities (Artmann et al., 2017).

The evaluation of LEAP quality in our study revealed the strengths and weaknesses that require careful consideration to ensure high quality plans. This provides an opportunity for environmental protection agencies (EPAs) to improve the LEAPs in the upcoming updating processes. We expect that the protocol developed in this study can be used by LEAP coordinating agencies worldwide so that future plans will reach the "desirable standard based on accepted plan quality standards", as requested by Berke and Godschalk (2009). The findings of our study could be directly useful for other countries experiencing the Europeanization of 
environmental planning as they have to meet similar requirements for environmental action plans. Other developing countries sharing similar environmental issues might benefit from the findings since the identified weaknesses can guide planners in other areas to issues that require special attention. Despite political, economic, social and cultural differences between Romania and other countries, the findings of this research may motive planners to improve public participation in plan-making which has been a prominent issue in many developing countries worldwide (Fonseca et al., 2017; Khosravi et al., 2019; Lovrić et al., 2018), as well as coordination across different hierarchical and horizontal levels, a common flaw for both developing (Yoseph-Paulus and Hindmarsh, 2018) and developed countries (Huh et al., 2017). Such multi-lateral collaborations are in particular needed in the face of pressing societal challenges such as climate change (Bäckstrand and Lövbrand, 2019).

\section{Acknowledgements}

This work was supported by the Romanian National Authority for Scientific Research, UEFISCDI [PN-III-P1-1.1-PD-2016-0248]. The authors would like to thank to Melissa Dawes for the English corrections on the manuscript. 


\section{References}

Artmann, M., 2014. Institutional efficiency of urban soil sealing management - From raising awareness to better implementation of sustainable development in Germany. Landsc. Urban Plan. 131, 83-95. doi:10.1016/J.LANDURBPLAN.2014.07.015

Artmann, M., Bastian, O., Grunewald, K., 2017. Using the Concepts of Green Infrastructure and Ecosystem Services to Specify Leitbilder for Compact and Green Cities-The Example of the Landscape Plan of Dresden (Germany). Sustainability 9, 198. doi:10.3390/su9020198

Baba, C., Chereches, R., Mora, C., Ticlau, T., 2009. Public Participation in Public Policy Process - Case Study in Seven Counties from North-Western Region of Romania. Transylvanian Rev. Adm. Sci. 5, 5-13.

Bäckstrand, K., Lövbrand, E., 2019. The Road to Paris: Contending Climate Governance Discourses in the Post-Copenhagen Era. J. Environ. Policy Plan. 21, 519-532. doi:10.1080/1523908X.2016.1150777

Badiu, D.L., Iojă, C.I., Pătroescu, M., Breuste, J., Artmann, M., Niță, M.R., Grădinaru, S.R., Hossu, C.A., Onose, D.A., 2016. Is urban green space per capita a valuable target to achieve cities' sustainability goals? Romania as a case study. Ecol. Indic. 70, 53-66. doi:10.1016/j.ecolind.2016.05.044

Baer, W.C., 1997. General Plan Evaluation Criteria: An Approach to Making Better Plans. J. Am. Plan. Assoc. 63, 329-344. doi:10.1080/01944369708975926

Berke, P., Godschalk, D., 2009. Searching for the Good Plan. J. Plan. Lit. 23, 227-240. doi:10.1177/0885412208327014

Berke, P., Smith, G., Lyles, W., 2012. Planning for Resiliency: Evaluation of State Hazard Mitigation Plans under the Disaster Mitigation Act. Nat. Hazards Rev. 13, 139-149. doi:10.1061/(ASCE)NH.1527-6996.0000063

Berke, P., Spurlock, D., Hess, G., Band, L., 2013. Local comprehensive plan quality and regional ecosystem protection: The case of the Jordan Lake watershed, North Carolina, U.S.A. Land use policy 31, 450-459. doi:10.1016/J.LANDUSEPOL.2012.08.009

Berke, P.R., Crawford, J., Dixon, J., Ericksen, N., 1999. Do Cooperative Environmental Planning Mandates Produce Good Plans? Empirical Results from the New Zealand Experience. Environ. Plan. B Plan. Des. 26, 643-664. doi:10.1068/b260643

Berke, P.R., Malecha, M.L., Yu, S., Lee, J., Masterson, J.H., 2019. Plan integration for resilience scorecard: evaluating networks of plans in six US coastal cities. J. Environ. Plan. Manag. 62, 901-920. doi:10.1080/09640568.2018.1453354

Bourguignon, D., 2018. Environment action programme. Living well, within the limits of our planet.

Bunnell, G., Jepson, E.J., 2011. The Effect of Mandated Planning on Plan Quality. J. Am. Plan. Assoc. 77, 338-353. doi:10.1080/01944363.2011.619951

Connell, D.J., Daoust-Filiatrault, L.-A., 2017. Better Than Good: Three Dimensions of Plan Quality. J. Plan. Educ. Res. 0739456X1770950. doi:10.1177/0739456X17709501

Conroy, M.M., Jun, H.-J., 2016. Planning process influences on sustainability in Ohio township plans. J. Environ. Plan. Manag. 59, 2007-2023. doi:10.1080/09640568.2015.1103709

Cortinovis, C., Geneletti, D., 2018. Ecosystem services in urban plans: What is there, and what is still needed for better decisions. Land use policy 70, 298-312.

doi:10.1016/J.LANDUSEPOL.2017.10.017

Danilov-Danil'yan, V.I., Reyf, I.E., 2018. Programs of Change: Stockholm—Rio De Janeiro- 
Johannesburg-Rio+20 BT - The Biosphere and Civilization: In the Throes of a Global Crisis, in: Danilov-Danil'yan, V.I., Reyf, I.E. (Eds.), . Springer International Publishing, Cham, pp. 127-136. doi:10.1007/978-3-319-67193-2 8

Davoudi, S., Cowell, R., White, I., Blanco, H., 2019. The Routledge Companion to Environmental Planning, 1st Editio. ed. Routledge.

Ericksen, N., Berke, P.R., Crawford, J., Dixon, J., 2017. Plan-making for Sustainability: The New Zealand Experience. Routledge.

Fonseca, A., Sánchez, L.E., Ribeiro, J.C.J., 2017. Reforming EIA systems: A critical review of proposals in Brazil. Environ. Impact Assess. Rev. 62, 90-97. doi:10.1016/J.EIAR.2016.10.002

Fostera, M., Peterson, M.N., Cubbage, F., McMahon, G., 2019. Evaluating natural resource planning for longleaf pine ecosystems in the Southeast United States. For. Policy Econ. 100, $142-153$.

Grădinaru, S.R., Hersperger, A.M., 2018. Green infrastructure in strategic spatial plans: Evidence from European urban regions. Urban For. Urban Green. doi:10.1016/J.UFUG.2018.04.018

Guyadeen, D., 2019. Evaluating the Quality of Municipal Official Plans in the Ontario-Greater Golden Horseshoe Region, Canada. J. Plan. Educ. Res. 0739456X19859648. doi: $10.1177 / 0739456$ X19859648

Guyadeen, D.R., 2017. Evaluation in Planning: An Investigation into Plan Quality and its Application to Official Plans in the Ontario-Greater Golden Horseshoe (GGH) Region. University of Waterloo.

Hopkins, L., 2001. Urban Development: The Logic of Making Plans. Island Press, Washington, $\mathrm{DC}$.

Horney, J., Nguyen, M., Salvesen, D., Dwyer, C., Cooper, J., Berke, P., 2017. Assessing the Quality of Rural Hazard Mitigation Plans in the Southeastern United States. J. Plan. Educ. Res. 37, 56-65. doi:10.1177/0739456X16628605

Horney, J.A., Naimi, A.I., Lyles, W., Simon, M., Salvesen, D., Berke, P., Horney, J.A., Naimi, A.I., Lyles, W., Simon, M., Salvesen, D., Berke, P., 2012. Assessing the Relationship Between Hazard Mitigation Plan Quality and Rural Status in a Cohort of 57 Counties from 3 States in the Southeastern U.S. Challenges 3, 183-193. doi:10.3390/challe3020183

Hossu, C.A., Ioja, I.C., Nita, M.R., Hartel, T., Badiu, D.L., Hersperger, A.M., 2017. Need for a cross-sector approach in protected area management. Land use policy 69, 586-597. doi:10.1016/j.landusepol.2017.10.012

Hossu, C.A., Ioja, I.C., Susskind, L.E., Badiu, D.L., Hersperger, A.M., 2018. Factors driving collaboration in natural resource conflict management: Evidence from Romania. Ambio 47, 816-830. doi:10.1007/s13280-018-1016-0

Huh, T., Park, Y., Yang, Y.J., 2017. Multilateral Governance for Climate Change Adaptation in S. Korea: The Mechanisms of Formulating Adaptation Policies. Sustain. . doi:10.3390/su9081364

IPPC, 2018. IPCC Summary for Policymakers. Global Warming of $1.5^{\circ} \mathrm{C}$. Geneva, Switzerland.

Khosravi, F., Jha-Thakur, U., Fischer, T.B., 2019. Evaluation of the environmental impact assessment system in Iran. Environ. Impact Assess. Rev. 74, 63-72. doi:10.1016/J.EIAR.2018.10.005

Kim, H., Tran, T., Kim, H.W., Tran, T., 2018. An Evaluation of Local Comprehensive Plans Toward Sustainable Green Infrastructure in US. Sustainability 10, 4143. 
doi:10.3390/su10114143

Krippendorff, K., 2013. Content analysis : an introduction to its methodology, Third Edit. ed. SAGE.

Laurian, L., Crawford, J., Day, M., Kouwenhoven, P., Mason, G., Ericksen, N., Beattie, L., 2010. Evaluating the Outcomes of Plans: Theory, Practice, and Methodology. Environ. Plan. B Plan. Des. 37, 740-757. doi:10.1068/b35051

Lovrić, N., Lovrić, M., Konold, W., 2018. A Grounded Theory approach for deconstructing the role of participation in spatial planning: Insights from Nature Park Medvednica, Croatia. For. Policy Econ. 87, 20-34. doi:10.1016/J.FORPOL.2017.11.003

Lyles, W., Berke, P., Smith, G., 2014a. A comparison of local hazard mitigation plan quality in six states, USA. Landsc. Urban Plan. 122, 89-99. doi:10.1016/J.LANDURBPLAN.2013.11.010

Lyles, W., Berke, P., Smith, G., 2014b. Do planners matter? Examining factors driving incorporation of land use approaches into hazard mitigation plans. J. Environ. Plan. Manag. 57, 792-811. doi:10.1080/09640568.2013.768973

Lyles, W., Berke, P., Smith, G., 2012. Evaluation of Local Hazard Mitigation Plan Quality.

Lyles, W., Stevens, M., 2014. Plan Quality Evaluation 1994-2012. J. Plan. Educ. Res. 34, 433450. doi:10.1177/0739456X14549752

Manolache, S., Nita, A., Ciocanea, C.M., Popescu, V.D., Rozylowicz, L., 2018. Power, influence and structure in Natura 2000 governance networks. A comparative analysis of two protected areas in Romania. J. Environ. Manage. 212, 54-64. doi:10.1016/J.JENVMAN.2018.01.076

Markowitz, P., 2002. Guide to Implementing Local Environmental Action Programmes in Central and Eastern Europe - Trainers' Handbook. Montpelier and Szentendre.

Ministry of Environment, 2004. Handbook for developing and implementing local environmental action plans. Bucharest.

Mitincu, C.G., 2019. Romania's administrative sub-divisions [WWW Document]. URL http://geo-spatial.org/

Mueller, G.P., Hersperger, A.M., 2015. Implementing comprehensive plans: indicators for a task-sheet based performance evaluation process. J. Environ. Plan. Manag. 58, 2056-2081. doi:10.1080/09640568.2014.973482

NEPA, 2016. Report on EAPs status.

NIS, 2017. Population and Demographic Structure.

Nita, A., Rozylowicz, L., Manolache, S., Ciocănea, C.M., Miu, I.V., Popescu, V.D., 2016. Collaboration Networks in Applied Conservation Projects across Europe. PLoS One 11, e0164503. doi:10.1371/journal.pone.0164503

Norton, R.K., 2008. Using content analysis to evaluate local master plans and zoning codes. Land use policy 25, 432-454. doi:10.1016/J.LANDUSEPOL.2007.10.006

Norton, R.K., David, N.P., Buckman, S., Koman, P.D., 2018. Overlooking the coast: Limited local planning for coastal area management along Michigan's Great Lakes. Land use policy 71, 183-203. doi:10.1016/J.LANDUSEPOL.2017.11.049

Oskam, A.J., Feng, S., 2008. Sustainable land use under different institutional settings. NJAS Wageningen J. Life Sci. 55, 295-306. doi:10.1016/S1573-5214(08)80022-X

Petrescu-Mag, R.M., 2008. Environmental policies, institutions and legislation (in Romanian: Politici, institutii si legislaţie pentru mediu). „AcademicPres, Cluj-Napoca.

Petrişor, A.-I., 2015. Using CORINE data to look at deforestation in Romania: distribution and possible consequences. Urbanism 6, 83-90. 
PHARE Project RO 9804.04.01.001, 2001. Institutional and administrative building capacity for environmental policies coordination in order to comply to Acquis Communautaire.

Potts, R., 2017. The good, the bad, and the statutory: are statutory or non-statutory natural resource management plans higher in quality? J. Environ. Policy Plan. 19, 668-681. doi:10.1080/1523908X.2016.1265885

Purica, I., 2015. Climate Change events induced risk assessment and mapping as a basis for an insurance policy. Procedia Econ. Financ. 22, 495-501. doi:10.1016/S2212-5671(15)002452

Puscasu, V., 2009. The house of many different ages, in: Knieling, J., Othengrafen, F. (Eds.), Planning Cultures in Europe. Decoding Cultural Phenomena in Urbanand Regional Planning. Ashgate Publishing Limited, England.

R Core Team, 2017. R: A language and environment for statistical computing.

Ramsey-Musolf, D., 2018. According to the Plan: Testing the Influence of Housing Plan Quality on Low-Income Housing Production. Urban Sci. 2.

Rudolf, S.C., Grădinaru, S.R., 2017. The quality and implementation of local plans: An integrated evaluation. Environ. Plan. B Urban Anal. City Sci. 239980831773707. doi:10.1177/2399808317737070

Spurlock, D., 2018. Do mandates matter for plan quality? Jurisdictional aggregation for a watershed level comparison. J. Environ. Plan. Manag. 61, 2257-2279. doi:10.1080/09640568.2017.1391070

Steelman, T.A., Hess, G.R., 2009. Effective Protection of Open Space: Does Planning Matter? Environ. Manage. 44, 93-104. doi:10.1007/s00267-009-9272-1

Stevens, M.R., 2013. Evaluating the Quality of Official Community Plans in Southern British Columbia. J. Plan. Educ. Res. 33, 471-490. doi:10.1177/0739456X13505649

Stevens, M.R., Lyles, W., Berke, P.R., 2014. Measuring and Reporting Intercoder Reliability in Plan Quality Evaluation Research. J. Plan. Educ. Res. 34, 77-93. doi:10.1177/0739456X13513614

Susskind, L., Cruikshank, J.L., 2006. Breaking Robert's rules : the new way to run your meeting, build consensus, and get results. Oxford University Press.

Tang, Z., 2008. Evaluating local coastal zone land use planning capacities in California. Ocean Coast. Manag. 51, 544-555. doi:10.1016/J.OCECOAMAN.2008.06.001

Tang, Z., Bright, E., Brody, S., 2008. Evaluating California Local Land Use Plan's Environmental Impact Reports. Community Reg. Plan. Progr. Fac. Sch. Creat. Act.

Tang, Z., Brody, S.D., 2009. Linking Planning Theories with Factors Influencing Local Environmental-Plan Quality. Environ. Plan. B Plan. Des. 36, 522-537. doi:10.1068/b34076

Vasile, P., Holt, A.G., 2014. The Strategy Of Financing The Environmental Projects Through The National Action Plan For Environment In Romania. Ann. - Econ. Ser. Constantin Brancusi Univ. Fac. Econ. 3, 70-73.

Verdini, G., Rogers, A.P., Veldpaus, L., Juma, M., Fayad, S., Zhou, J., 2016. The HUL Guidebook: Managing Heritage in Dynamic and Constantly Changing Urban Environments.

Victor, D.G., Akimoto, K., Kaya, Y., Yamaguchi, M., Cullenward, D., Hepburn, C., 2017. Prove Paris was more than paper promises. Nature 548, 25-27. doi:10.1038/548025a

Woodruff, S.C., Regan, P., 2019. Quality of national adaptation plans and opportunities for improvement. Mitig. Adapt. Strateg. Glob. Chang. 24, 53-71. doi:10.1007/s11027-0189794-z

Yoseph-Paulus, R., Hindmarsh, R., 2018. Addressing inadequacies of sectoral coordination and 
local capacity building in Indonesia for effective climate change adaptation. Clim. Dev. 10, 35-48. doi:10.1080/17565529.2016.1184609

Zeiger, B., Gunton, T., Rutherford, M., 2019. Toward sustainable development: A methodology for evaluating environmental planning systems. Sustain. Dev. 27, 13-24. 


\section{Appendix 1}

Table A1: Protocol to assess the Local Environmental Action Plans. Results of the final analysis

\begin{tabular}{|c|c|c|c|c|}
\hline Documentation & Coding & Mode & Alpha $^{1}$ & Decision $^{2}$ \\
\hline \multicolumn{5}{|l|}{ 1. Goals } \\
\hline $\begin{array}{l}\text { 1.1. Does the plan include a clearly defined goal for } \\
\text { improving the overall environmental quality of the county? }\end{array}$ & binary & $10(63 \%)$ & 1 & \\
\hline 1.2. Are the overall environmental goals clearly identified? & binary & $10(63 \%)$ & 1 & \\
\hline $\begin{array}{l}\text { 1.3. Are the specific environmental goals clearly } \\
\text { identified? }\end{array}$ & binary & $0(94 \%)$ & 0.786 & $\begin{array}{l}\text { reassessed } \\
\text { and } \\
\text { reconciled }\end{array}$ \\
\hline $\begin{array}{l}\text { 1.4. Are the specific environmental goals clearly linked to } \\
\text { the county's specific environmental problems? }\end{array}$ & binary & $0(94 \%)$ & 0.786 & $\begin{array}{l}\text { reassessed } \\
\text { and } \\
\text { reconciled }\end{array}$ \\
\hline \multicolumn{5}{|l|}{ 2. Fact bases } \\
\hline $\begin{array}{l}\text { 2.1. Does the plan include a separate section that precisely } \\
\text { describes the county's general environmental conditions (i.e., } \\
\text { topography, climate, landscapes, natural resources)? }\end{array}$ & $\begin{array}{l}\text { three-level } \\
\text { ordinal }\end{array}$ & $10(69 \%)$ & 0.848 & reconciled \\
\hline $\begin{array}{l}2.2 . \quad \text { Does the plan include a description of the present state } \\
\text { of the county's main environmental issues? }\end{array}$ & $\begin{array}{l}\text { three-level } \\
\text { ordinal }\end{array}$ & $10(100 \%)$ & 1 & \\
\hline $\begin{array}{l}\text { 2.3. Does the plan include a description of the future state } \\
\text { of the county's main environmental issues? }\end{array}$ & $\begin{array}{l}\text { three-level } \\
\text { ordinal }\end{array}$ & $0(50 \%)$ & 0.85 & reconciled \\
\hline \multicolumn{5}{|l|}{ 2.4. $\quad$ Tables } \\
\hline 2.4.1. Are facts presented in tables? & binary & $10(100 \%)$ & 1 & \\
\hline $\begin{array}{l}\text { 2.4.2. Do the tables display information that is relevant and } \\
\text { comprehensible? }\end{array}$ & $\begin{array}{l}\text { three-level } \\
\text { ordinal }\end{array}$ & $10(100 \%)$ & 1 & \\
\hline 2.4.3. Do the tables have a title listed? & $\begin{array}{l}\text { three-level } \\
\text { ordinal }\end{array}$ & $10(78 \%)$ & 1 & \\
\hline 2.4.4. Do the tables have a data source listed? & $\begin{array}{l}\text { three-level } \\
\text { ordinal }\end{array}$ & $5(69 \%)$ & 0.932 & reconciled \\
\hline \multicolumn{5}{|l|}{ 2.5. Diagrams/Graphs } \\
\hline 2.5.1. Are facts presented in diagrams/graphs? & binary & $10(91 \%)$ & 1 & \\
\hline $\begin{array}{l}\text { 2.5.2. Do the diagrams/graphs display information that is } \\
\text { relevant and comprehensible? }\end{array}$ & $\begin{array}{l}\text { three-level } \\
\text { ordinal }\end{array}$ & $10(91 \%)$ & 0.844 & reconciled \\
\hline 2.5.3. Do the diagrams/graphs have a title and a legend listed? & $\begin{array}{l}\text { three-level } \\
\text { ordinal }\end{array}$ & $10(91 \%)$ & 1 & \\
\hline 2.5.4. Do the diagrams/graphs have a data source listed? & $\begin{array}{l}\text { three-level } \\
\text { ordinal }\end{array}$ & $5(44 \%)$ & 0.905 & reconciled \\
\hline \multicolumn{5}{|l|}{ 2.6. $\quad$ Maps } \\
\hline 2.6.1. Are facts presented in maps? & binary & $10(66 \%)$ & 1 & \\
\hline $\begin{array}{l}\text { 2.6.2. Do the maps display information that is relevant and } \\
\text { comprehensible? }\end{array}$ & $\begin{array}{l}\text { three-level } \\
\text { ordinal }\end{array}$ & $10(59 \%)$ & 0.941 & reconciled \\
\hline
\end{tabular}




\begin{tabular}{|c|c|c|c|c|}
\hline 2.6.3. Do the maps have a title and a legend listed? & $\begin{array}{l}\text { three-level } \\
\text { ordinal }\end{array}$ & $10(53 \%)$ & 1 & \\
\hline 2.6.4. Do the maps have a data source listed? & $\begin{array}{l}\text { three-level } \\
\text { ordinal }\end{array}$ & $0(84 \%)$ & 1 & \\
\hline 2.7. Are fact presented in other graphical formats? & binary & $10(53 \%)$ & 1 & \\
\hline \multicolumn{5}{|l|}{ 3. Policies } \\
\hline \multicolumn{5}{|l|}{ 3.1. Management of natural resources } \\
\hline $\begin{array}{l}\text { 3.1.1. Does the plan include at least one action related to air } \\
\text { quality management? }\end{array}$ & binary & $10(100 \%)$ & 1 & \\
\hline $\begin{array}{l}\text { 3.1.2. Does the plan include at least one action related to water } \\
\text { quality management? }\end{array}$ & binary & $10(100 \%)$ & 1 & \\
\hline $\begin{array}{l}\text { 3.1.3. Does the plan include at least one action related to soil } \\
\text { quality management? }\end{array}$ & binary & $10(100 \%)$ & 1 & \\
\hline $\begin{array}{l}\text { 3.1.4. Does the plan include at least one action related to } \\
\text { agricultural land management? }\end{array}$ & binary & $10(91 \%)$ & 0.842 & reconciled \\
\hline $\begin{array}{l}\text { 3.1.5. Does the plan include at least one action related to } \\
\text { wildlife management? }\end{array}$ & binary & $10(100 \%)$ & 1 & \\
\hline $\begin{array}{l}\text { 3.1.6. Does the plan include at least one action related to } \\
\text { forestry management? }\end{array}$ & binary & $10(84 \%)$ & 0.873 & reconciled \\
\hline \multicolumn{5}{|l|}{ 3.2. $\quad$ Environmental nuisances } \\
\hline $\begin{array}{l}\text { 3.2.1. Does the plan include at least one action to mitigate the } \\
\text { hazards' impacts? }\end{array}$ & binary & $10(97 \%)$ & $0.97^{3}$ & reconciled \\
\hline $\begin{array}{l}\text { 3.2.2. Does the plan include at least one action to mitigate } \\
\text { waste induced problems? }\end{array}$ & binary & $10(100 \%)$ & 1 & \\
\hline $\begin{array}{l}\text { 3.2.3. Does the plan include at least one action to mitigate the } \\
\text { negative impacts of transportation? }\end{array}$ & binary & $10(97 \%)$ & 1 & \\
\hline $\begin{array}{l}\text { 3.2.4. Does the plan include at least one action related to } \\
\text { mitigating urbanization problems? }\end{array}$ & binary & $10(94 \%)$ & $0.94^{3}$ & reconciled \\
\hline $\begin{array}{l}\text { 3.2.5. Does the plan include at least one action to limit } \\
\text { consumptive activities such as hunting, fishing and timber } \\
\text { harvesting? }\end{array}$ & binary & $0(53 \%)$ & 1 & \\
\hline \multicolumn{5}{|l|}{ 3.3. $\quad$ Institutional and administrative capacity } \\
\hline $\begin{array}{l}\text { 3.3.1. Does the plan include at least one action related to the } \\
\text { efficiency of the environmental institutions? }\end{array}$ & binary & $10(78 \%)$ & 1 & \\
\hline $\begin{array}{l}\text { 3.3.2. Does the plan include at least one action related to } \\
\text { increasing coordination? }\end{array}$ & binary & $10(81 \%)$ & 0.82 & reconciled \\
\hline \multicolumn{5}{|l|}{$\begin{array}{l}\text { 3.4. Environmental education awareness, public health } \\
\text { and recreation }\end{array}$} \\
\hline $\begin{array}{l}\text { 3.4.1. Does the plan include at least one action related to } \\
\text { environmental education awareness? }\end{array}$ & binary & $10(100 \%)$ & 1 & \\
\hline $\begin{array}{l}\text { 3.4.2. Does the plan include at least one action related to } \\
\text { improving public health in relation to environmental } \\
\text { pollution? }\end{array}$ & binary & $10(75 \%)$ & 0.836 & reconciled \\
\hline
\end{tabular}




\begin{tabular}{|c|c|c|c|c|}
\hline $\begin{array}{l}\text { 3.4.3. Does the plan include at least one action to improve } \\
\text { recreational opportunities? }\end{array}$ & binary & $10(97 \%)$ & $0.97^{3}$ & reconciled \\
\hline \multicolumn{5}{|l|}{ 4. Public participation in plan creation } \\
\hline $\begin{array}{l}\text { 4.1. Does the plan include a separate section that describes the } \\
\text { public participation process during the preparation of the plan? }\end{array}$ & $\begin{array}{l}\text { three-level } \\
\text { ordinal }\end{array}$ & $5(91 \%)$ & 1 & \\
\hline $\begin{array}{l}\text { 4.2. Does the plan identify relevant stakeholders (i.e., public } \\
\text { officials, private companies, NGOs, etc.)? }\end{array}$ & $\begin{array}{l}\text { three-level } \\
\text { ordinal }\end{array}$ & $10(91 \%)$ & 1 & \\
\hline $\begin{array}{l}\text { 4.3. Does the plan include a section that explains why the } \\
\text { stakeholders identified in the plan were involved? }\end{array}$ & $\begin{array}{l}\text { three-level } \\
\text { ordinal }\end{array}$ & $5(81 \%)$ & 0.689 & reconciled \\
\hline $\begin{array}{l}\text { 4.4. Does the plan include any information about when the } \\
\text { stakeholders were invited to participate? }\end{array}$ & $\begin{array}{l}\text { three-level } \\
\text { ordinal }\end{array}$ & $10(75 \%)$ & 0.921 & reconciled \\
\hline $\begin{array}{l}\text { 4.5. Does the plan specify which participation techniques were } \\
\text { used (i.e., workshops, surveys, preliminary drafts circulated } \\
\text { for public comment, etc.)? }\end{array}$ & $\begin{array}{l}\text { three-level } \\
\text { ordinal }\end{array}$ & $10(72 \%)$ & 0.853 & reconciled \\
\hline $\begin{array}{l}\text { 4.6. Does the plan include a section that explains whether the } \\
\text { input obtained from the stakeholders during the participation } \\
\text { process was included in plan? }\end{array}$ & $\begin{array}{l}\text { three-level } \\
\text { ordinal }\end{array}$ & $5(63 \%)$ & 0.739 & reconciled \\
\hline \multicolumn{5}{|l|}{ 5. Plan provisions for implementation and monitoring } \\
\hline \multicolumn{5}{|l|}{ 5.1. Implementation } \\
\hline $\begin{array}{l}\text { 5.1.1. Does the plan include a separate section/subsection that } \\
\text { addresses what needs to be done (any recommendations) to } \\
\text { implement the plan? }\end{array}$ & $\begin{array}{l}\text { three-level } \\
\text { ordinal }\end{array}$ & $10(94 \%)$ & $0.94^{3}$ & reconciled \\
\hline 5.1.2. Are timelines for implementation generally specified? & $\begin{array}{l}\text { three-level } \\
\text { ordinal }\end{array}$ & $10(100 \%)$ & 1 & \\
\hline $\begin{array}{l}\text { 5.1.3. Does the plan generally identify specific organizations } \\
\text { with responsibility for implementation? }\end{array}$ & $\begin{array}{l}\text { three-level } \\
\text { ordinal }\end{array}$ & $10(100 \%)$ & 1 & \\
\hline $\begin{array}{l}\text { 5.1.4. Are specific sources of funding identified to implement } \\
\text { the plan? }\end{array}$ & $\begin{array}{l}\text { three-level } \\
\text { ordinal }\end{array}$ & $10(75 \%)$ & 1 & \\
\hline 5.1.5. Are specify targets for implementation identified? & $\begin{array}{l}\text { three-level } \\
\text { ordinal }\end{array}$ & $10(100 \%)$ & 1 & \\
\hline $\begin{array}{l}\text { 5.1.6. Are concrete policies/actions generally presented along } \\
\text { with cost estimations for their implementation? }\end{array}$ & $\begin{array}{l}\text { three-level } \\
\text { ordinal }\end{array}$ & $0(63 \%)$ & 1 & \\
\hline \multicolumn{5}{|l|}{ 5.2. Monitoring } \\
\hline $\begin{array}{l}\text { 5.2.1. Does the plan contain a section/subsection that } \\
\text { addresses monitoring the performance in terms of goal } \\
\text { achievement and implementation of policies/actions? }\end{array}$ & $\begin{array}{l}\text { three-level } \\
\text { ordinal }\end{array}$ & $5(66 \%)$ & 0.869 & reconciled \\
\hline $\begin{array}{l}\text { 5.2.2. Does the plan contain a section that addresses how } \\
\text { monitoring data was collected? }\end{array}$ & $\begin{array}{l}\text { three-level } \\
\text { ordinal }\end{array}$ & $5(78 \%)$ & 0.809 & reconciled \\
\hline 5.2.3. Are timelines for monitoring generally specified? & $\begin{array}{l}\text { three-level } \\
\text { ordinal }\end{array}$ & $0(69 \%)$ & 0.932 & reconciled \\
\hline $\begin{array}{l}\text { 5.2.4. Does the plan generally identify organizations with } \\
\text { responsibility for monitoring progress? }\end{array}$ & $\begin{array}{l}\text { three-level } \\
\text { ordinal }\end{array}$ & $10(59 \%)$ & 0.886 & reconciled \\
\hline
\end{tabular}




\begin{tabular}{|c|c|c|c|c|}
\hline $\begin{array}{l}5.2 .5 . \text { Is there a plan for evaluating progress of the policies } \\
\text { being implemented? }\end{array}$ & $\begin{array}{l}\text { three-level } \\
\text { ordinal }\end{array}$ & $5(69 \%)$ & 0.813 & reconciled \\
\hline 5.2.6. Is a method for updating the plan indicated? & $\begin{array}{l}\text { three-level } \\
\text { ordinal }\end{array}$ & $5(59 \%)$ & 0.891 & reconciled \\
\hline 5.2.7. Is there a timetable for updating the plan? & $\begin{array}{l}\text { three-level } \\
\text { ordinal }\end{array}$ & $5(78 \%)$ & 0.914 & reconciled \\
\hline $\begin{array}{l}\text { 5.2.8. Does the plan contain a section that addresses public } \\
\text { involvement in updates/monitoring? }\end{array}$ & $\begin{array}{l}\text { three-level } \\
\text { ordinal }\end{array}$ & $5(69 \%)$ & 0.93 & reconciled \\
\hline Policy Focus & Coding & Mode & Alpha $^{1}$ & Decision $^{2}$ \\
\hline \multicolumn{5}{|l|}{ 6. Maximize stability } \\
\hline $\begin{array}{l}\text { 6.1. Does the plan use strong statements in the formulation of } \\
\text { policies/actions that are generally mandatory? }\end{array}$ & $\begin{array}{l}\text { three-level } \\
\text { ordinal }\end{array}$ & $10(100 \%)$ & 1 & \\
\hline $\begin{array}{l}\text { 6.2. Does the plan use clear language in the formulation of } \\
\text { policies/actions? }\end{array}$ & $\begin{array}{l}\text { three-level } \\
\text { ordinal }\end{array}$ & $10(100 \%)$ & 1 & \\
\hline $\begin{array}{l}\text { 6.3. Are any enforceable mechanisms (such as emissions } \\
\text { limitations and standards, zoning ordinances and plans, } \\
\text { regulations, etc.) specified in the formulation of } \\
\text { policies/actions? }\end{array}$ & $\begin{array}{l}\text { three-level } \\
\text { ordinal }\end{array}$ & $5(97 \%)$ & $0.94^{3}$ & reconciled \\
\hline \multicolumn{5}{|l|}{ 7. Minimize uncertainty } \\
\hline 7.1. Are policies/actions clearly linked to specific goals? & $\begin{array}{l}\text { three-level } \\
\text { ordinal }\end{array}$ & $10(100 \%)$ & 1 & \\
\hline $\begin{array}{l}\text { 7.2. Are the policies/actions clearly linked to an } \\
\text { implementation plan? }\end{array}$ & $\begin{array}{l}\text { three-level } \\
\text { ordinal }\end{array}$ & $10(100 \%)$ & 1 & \\
\hline $\begin{array}{l}\text { 7.3. Are the policies/actions consistent and mutually } \\
\text { supportive? }\end{array}$ & $\begin{array}{l}\text { three-level } \\
\text { ordinal }\end{array}$ & $10(100 \%)$ & 1 & \\
\hline $\begin{array}{l}\text { 7.4. Does monitoring include indicators to gauge goal } \\
\text { achievement and effectiveness of policies/actions? }\end{array}$ & $\begin{array}{l}\text { three-level } \\
\text { ordinal }\end{array}$ & $10(97 \%)$ & 1 & \\
\hline \multicolumn{5}{|l|}{ 8. Integrate public priorities across jurisdictions } \\
\hline $\begin{array}{l}\text { 8.1. Does the plan discuss intergovernmental coordination } \\
\text { (i.e., coordination with the state/regional agencies or the state } \\
\text { planning initiatives - vertical coordination)? }\end{array}$ & $\begin{array}{l}\text { three-level } \\
\text { ordinal }\end{array}$ & $5(69 \%)$ & 0.86 & reconciled \\
\hline $\begin{array}{l}\text { 8.2. Does the plan include the main planning } \\
\text { documents/concepts of higher institutional levels (i.e., national } \\
\text { strategies National Strategy for Sustainable Development, } \\
\text { national plans National Environmental Action Plan, regional } \\
\text { plans - Regional Development Plan)? }\end{array}$ & $\begin{array}{l}\text { three-level } \\
\text { ordinal }\end{array}$ & $5(69 \%)$ & 0.937 & reconciled \\
\hline $\begin{array}{l}\text { 8.3. Does the plan discuss coordination with a neighboring } \\
\text { county (i.e., coordination with the planning initiatives of a } \\
\text { neighboring county horizontal coordination)? }\end{array}$ & $\begin{array}{l}\text { three-level } \\
\text { ordinal }\end{array}$ & $0(75 \%)$ & 0.82 & reconciled \\
\hline $\begin{array}{l}\text { 8.4. Does the plan discuss coordination with other local (from } \\
\text { the same county) plans and programs intercommunal } \\
\text { coordination)? }\end{array}$ & $\begin{array}{l}\text { three-level } \\
\text { ordinal }\end{array}$ & $5(88 \%)$ & 0.726 & reconciled \\
\hline
\end{tabular}




\begin{tabular}{|c|c|c|c|c|}
\hline $\begin{array}{l}\text { 8.5. Does the plan include the main planning } \\
\text { documents/concepts at the county level (i.e., county plans, } \\
\text { PATJ, building ordinances)? }\end{array}$ & $\begin{array}{l}\text { three-level } \\
\text { ordinal }\end{array}$ & $5(72 \%)$ & 0.924 & reconciled \\
\hline $\begin{array}{l}\text { 8.6. Are the main planning documents and concepts the local } \\
\text { plan builds on described in detail, or is it precisely explained } \\
\text { how the local plan conforms to these documents } \\
\text { (independently of whether these documents come from higher } \\
\text { institutional levels or from the municipality)? }\end{array}$ & $\begin{array}{l}\text { three-level } \\
\text { ordinal }\end{array}$ & $5(41 \%)$ & 0.906 & reconciled \\
\hline \multicolumn{5}{|l|}{ 9. Accommodate flexibility } \\
\hline $\begin{array}{l}\text { 9.1. Are any exceptions to the general } \\
\text { rules/regulations/recommendations addressed in the } \\
\text { formulation of policies/actions? }\end{array}$ & $\begin{array}{l}\text { three-level } \\
\text { ordinal }\end{array}$ & $0(94 \%)$ & $0.97^{3}$ & reconciled \\
\hline $\begin{array}{l}\text { 9.2. Are any governance mechanisms addressed in the } \\
\text { formulation of policies/actions? }\end{array}$ & $\begin{array}{l}\text { three-level } \\
\text { ordinal }\end{array}$ & $5(100 \%)$ & 1 & \\
\hline Discourse & Coding & Mode & Alpha $^{1}$ & Decision $^{2}$ \\
\hline \multicolumn{5}{|l|}{ 10. Legibility } \\
\hline 10.1. Does the plan include an executive summary? & binary & $10(50 \%)$ & 1 & \\
\hline 10.2. Does the plan include a table of contents? & binary & $10(78 \%)$ & 1 & \\
\hline 10.3. Does the plan include a reference list at the end? & binary & $0(88 \%)$ & 1 & \\
\hline $\begin{array}{l}\text { 10.4. Does the plan use illustrations (pictures, diagrams, maps, } \\
\text { tables, etc.?) outside the fact base section? }\end{array}$ & binary & $10(100 \%)$ & 1 & \\
\hline 10.5. Is the plan well written, clear and concise? & binary & $10(100 \%)$ & 1 & \\
\hline $\begin{array}{l}\text { 10.6. Does the plan have a visually attractive format (columns } \\
\text { not too wide, adequate line spacing, etc.)? }\end{array}$ & binary & $10(94 \%)$ & 0.786 & reconciled \\
\hline 10.7. Does the plan discuss its purpose? & binary & $0(53 \%)$ & 1 & \\
\hline $\begin{array}{l}\text { 10.8. Does the plan provide an explanation of the planning } \\
\text { process? }\end{array}$ & binary & $10(84 \%)$ & 0.892 & reconciled \\
\hline 10.9. How did the plan score in goals articulation? & $\begin{array}{l}\text { three-level } \\
\text { ordinal }\end{array}$ & $5(56 \%)$ & 0.944 & reconciled \\
\hline 10.10. How did the plan score in policies/actions articulation? & $\begin{array}{l}\text { three-level } \\
\text { ordinal }\end{array}$ & $10(97 \%)$ & 1 & \\
\hline $\begin{array}{l}\text { 10.11. How did the plan score in the implementation and } \\
\text { monitoring provisions? }\end{array}$ & $\begin{array}{l}\text { three-level } \\
\text { ordinal }\end{array}$ & $5(66 \%)$ & 0.935 & reconciled \\
\hline \multicolumn{5}{|l|}{ 11. Accuracy } \\
\hline $\begin{array}{l}\text { 11.1. How did the plan score in descriptive and analytical } \\
\text { fact base? }\end{array}$ & $\begin{array}{l}\text { three-level } \\
\text { ordinal }\end{array}$ & $10(59 \%)$ & 1 & \\
\hline \multicolumn{5}{|l|}{ 12. Legitimacy } \\
\hline 12.1. How did the plan score regarding legibility? & $\begin{array}{l}\text { three-level } \\
\text { ordinal }\end{array}$ & $5(50 \%)$ & 0.942 & reconciled \\
\hline 12.2. How did the plan score in public participation? & $\begin{array}{l}\text { three-level } \\
\text { ordinal }\end{array}$ & $5(53 \%)$ & 0.773 & $\begin{array}{l}\text { reassessed } \\
\text { and } \\
\text { reconciled }\end{array}$ \\
\hline 13. Sincerity & & & & \\
\hline
\end{tabular}




\begin{tabular}{|l|l|l|l|l|}
\hline $\begin{array}{l}\text { 13.1. How did the plan score in implementation and } \\
\text { monitoring? }\end{array}$ & $\begin{array}{l}\text { three-level } \\
\text { ordinal }\end{array}$ & $5(66 \%)$ & 0.935 & reconciled \\
\hline $\begin{array}{l}\text { 12.2. How did the plan score in minimizing uncertainty? } \\
\text { three-level } \\
\text { ordinal }\end{array}$ & $10(100 \%)$ & 1 & \\
\hline $\begin{array}{l}\text { 13.3. How did the plan score in integrating public priorities } \\
\text { across jurisdictions }\end{array}$ & $\begin{array}{l}\text { three-level } \\
\text { ordinal }\end{array}$ & $0(66 \%)$ & 0.815 & reconciled \\
\hline $\begin{array}{l}\text { 13.4. Does the plan contain a section with a discussion of how } \\
\text { many actions were implemented? }\end{array}$ & binary & $0(59 \%)$ & 1 & \\
\hline
\end{tabular}

${ }^{1}$ Value of Krippendorff's alpha

${ }^{2}$ The scores from both coders were either (i) reassessed and reconciled or (ii) only reconciled and included in the analysis

${ }^{3}$ There is a lack of variability in codes and the value of Krippendorff's alpha is misleadingly low. In such cases, authors recommend reporting percent agreement (Stevens et al., 2014) 
Appendix 2

Table A2: Results of the content analysis for individual LEAPs

\begin{tabular}{|c|c|c|c|c|c|c|c|c|c|c|c|c|c|c|c|c|}
\hline \multirow[b]{2}{*}{ County } & \multicolumn{5}{|c|}{ Documentation } & \multirow[b]{2}{*}{ Mean } & \multicolumn{4}{|c|}{$\begin{array}{l}\text { Policy focus } \\
\end{array}$} & \multirow[b]{2}{*}{ Mean } & \multicolumn{4}{|c|}{ Discourse } & \multirow[b]{2}{*}{ Mean } \\
\hline & Goals & $\begin{array}{l}\text { Fact } \\
\text { bases }\end{array}$ & Policies & $\begin{array}{c}\text { Public } \\
\text { participation } \\
\text { in plan } \\
\text { creation }\end{array}$ & $\begin{array}{c}\text { Plan provisions } \\
\text { for } \\
\text { implementation } \\
\text { and monitoring }\end{array}$ & & $\begin{array}{l}\text { Maximizi } \\
\text { ng } \\
\text { stability }\end{array}$ & $\begin{array}{l}\text { Minimizing } \\
\text { uncertainty }\end{array}$ & $\begin{array}{c}\text { Integrating } \\
\text { public priorities } \\
\text { across } \\
\text { jurisdictions }\end{array}$ & $\begin{array}{l}\text { Accommodati } \\
\text { ng flexibility }\end{array}$ & & Legibility & Accuracy & Legitimacy & Sincerity & \\
\hline Alba & 0.00 & 5.63 & 8.13 & 6.67 & 7.86 & 5.65 & 8.33 & 10.00 & 2.50 & 2.50 & 5.83 & 7.27 & 5.00 & 7.50 & 7.50 & 6.82 \\
\hline Arad & 5.00 & 3.44 & 10.00 & 6.67 & 6.43 & 6.31 & 8.33 & 10.00 & 3.33 & 2.50 & 6.04 & 7.27 & 0.00 & 7.50 & 6.25 & 5.26 \\
\hline Argeș & 5.00 & 6.25 & 9.38 & 8.33 & 7.14 & 7.22 & 8.33 & 10.00 & 4.17 & 2.50 & 6.25 & 7.73 & 5.00 & 10.00 & 5.00 & 6.93 \\
\hline Bihor & 10.00 & 8.44 & 9.38 & 5.83 & 5.36 & 7.80 & 8.33 & 10.00 & 3.33 & 5.00 & 6.67 & 6.82 & 10.00 & 5.00 & 3.75 & 6.39 \\
\hline $\begin{array}{l}\text { Bistrița } \\
\text { Năsăud }\end{array}$ & 0.00 & 7.50 & 9.38 & 7.50 & 6.07 & 6.09 & 8.33 & 10.00 & 3.33 & 2.50 & 6.04 & 6.82 & 10.00 & 7.50 & 3.75 & 7.02 \\
\hline Brăila & 5.00 & 5.94 & 8.75 & 7.50 & 5.71 & 6.58 & 8.33 & 10.00 & 4.17 & 2.50 & 6.25 & 7.27 & 5.00 & 10.00 & 3.75 & 6.51 \\
\hline Braşov & 0.00 & 8.75 & 10.00 & 5.83 & 8.21 & 6.56 & 8.33 & 10.00 & 5.00 & 2.50 & 6.46 & 7.27 & 10.00 & 7.50 & 8.75 & 8.38 \\
\hline Buzău & 5.00 & 2.81 & 9.38 & 6.67 & 6.43 & 6.06 & 8.33 & 10.00 & 4.17 & 2.50 & 6.25 & 5.45 & 0.00 & 5.00 & 3.75 & 3.55 \\
\hline Călărași & 5.00 & 7.81 & 9.38 & 8.33 & 3.93 & 6.89 & 8.33 & 10.00 & 5.83 & 2.50 & 6.67 & 7.73 & 10.00 & 10.00 & 3.75 & 7.87 \\
\hline $\begin{array}{l}\text { Caraș } \\
\text { Severin }\end{array}$ & 0.00 & 8.44 & 9.38 & 7.50 & 6.43 & 6.35 & 10.00 & 10.00 & 2.50 & 2.50 & 6.25 & 6.82 & 10.00 & 7.50 & 6.25 & 7.64 \\
\hline Constanța & 0.00 & 5.63 & 8.13 & 5.83 & 5.36 & 4.99 & 8.33 & 10.00 & 5.83 & 2.50 & 6.67 & 5.91 & 5.00 & 5.00 & 5.00 & 5.23 \\
\hline Covasna & 0.00 & 8.44 & 9.38 & 6.67 & 7.50 & 6.40 & 8.33 & 10.00 & 5.83 & 2.50 & 6.67 & 6.36 & 10.00 & 5.00 & 8.75 & 7.53 \\
\hline Dâmbovița & 5.00 & 8.13 & 8.13 & 5.83 & 6.43 & 6.70 & 8.33 & 10.00 & 3.33 & 2.50 & 6.04 & 6.36 & 10.00 & 5.00 & 6.25 & 6.90 \\
\hline Dolj & 5.00 & 8.75 & 8.13 & 4.17 & 6.07 & 6.42 & 8.33 & 10.00 & 2.50 & 2.50 & 5.83 & 7.27 & 10.00 & 5.00 & 3.75 & 6.51 \\
\hline Galați & 0.00 & 3.44 & 10.00 & 6.67 & 6.79 & 5.38 & 8.33 & 10.00 & 5.83 & 2.50 & 6.67 & 6.82 & 0.00 & 5.00 & 5.00 & 4.20 \\
\hline Giurgiu & 5.00 & 6.88 & 8.13 & 9.17 & 7.86 & 7.41 & 8.33 & 10.00 & 8.33 & 2.50 & 7.29 & 8.64 & 5.00 & 10.00 & 10.00 & 8.41 \\
\hline Harghita & 0.00 & 5.63 & 10.00 & 6.67 & 7.14 & 5.89 & 8.33 & 10.00 & 5.83 & 2.50 & 6.67 & 6.36 & 5.00 & 5.00 & 8.75 & 6.28 \\
\hline Hunedoara & 0.00 & 5.00 & 5.63 & 8.33 & 5.71 & 4.94 & 8.33 & 10.00 & 4.17 & 2.50 & 6.25 & 3.64 & 5.00 & 5.00 & 3.75 & 4.35 \\
\hline Iași & 0.00 & 9.06 & 10.00 & 8.33 & 6.43 & 6.76 & 8.33 & 10.00 & 5.00 & 2.50 & 6.46 & 6.82 & 10.00 & 7.50 & 7.50 & 7.95 \\
\hline Maramureș & 5.00 & 8.13 & 9.38 & 6.67 & 7.86 & 7.41 & 8.33 & 10.00 & 4.17 & 5.00 & 6.88 & 8.64 & 10.00 & 7.50 & 7.50 & 8.41 \\
\hline Mehedinți & 5.00 & 7.50 & 9.38 & 3.33 & 6.07 & 6.26 & 8.33 & 10.00 & 4.17 & 2.50 & 6.25 & 6.36 & 10.00 & 2.50 & 3.75 & 5.65 \\
\hline Mureș & 0.00 & 6.56 & 8.75 & 5.83 & 5.36 & 5.30 & 8.33 & 10.00 & 0.00 & 2.50 & 5.21 & 5.91 & 5.00 & 5.00 & 3.75 & 4.91 \\
\hline Olt & 5.00 & 9.06 & 8.75 & 7.50 & 6.43 & 7.35 & 8.33 & 7.50 & 3.33 & 2.50 & 5.42 & 6.36 & 10.00 & 7.50 & 3.75 & 6.90 \\
\hline
\end{tabular}




\begin{tabular}{|c|c|c|c|c|c|c|c|c|c|c|c|c|c|c|c|c|}
\hline Satu Mare & 10.00 & 9.06 & 8.75 & 6.67 & 5.36 & 7.97 & 8.33 & 10.00 & 4.17 & 2.50 & 6.25 & 6.82 & 10.00 & 5.00 & 3.75 & 6.39 \\
\hline Sibiu & 5.00 & 8.13 & 10.00 & 6.67 & 5.36 & 7.03 & 8.33 & 10.00 & 7.50 & 2.50 & 7.08 & 8.18 & 10.00 & 7.50 & 8.75 & 8.61 \\
\hline Suceava & 5.00 & 9.38 & 8.13 & 6.67 & 6.43 & 7.12 & 8.33 & 10.00 & 6.67 & 2.50 & 6.88 & 7.27 & 10.00 & 7.50 & 7.50 & 8.07 \\
\hline Teleorman & 5.00 & 8.75 & 8.13 & 8.33 & 7.14 & 7.47 & 8.33 & 10.00 & 4.17 & 2.50 & 6.25 & 7.73 & 10.00 & 10.00 & 5.00 & 8.18 \\
\hline Timiș & 5.00 & 7.81 & 10.00 & 6.67 & 6.07 & 7.11 & 8.33 & 10.00 & 5.83 & 2.50 & 6.67 & 7.27 & 10.00 & 7.50 & 5.00 & 7.44 \\
\hline Tulcea & 0.00 & 7.50 & 10.00 & 7.50 & 4.29 & 5.86 & 8.33 & 10.00 & 4.17 & 2.50 & 6.25 & 5.45 & 10.00 & 7.50 & 5.00 & 6.99 \\
\hline Vâlcea & 5.00 & 7.50 & 8.13 & 5.83 & 5.71 & 6.43 & 8.33 & 10.00 & 0.00 & 2.50 & 5.21 & 8.18 & 10.00 & 7.50 & 3.75 & 7.36 \\
\hline Vaslui & 5.00 & 5.94 & 8.75 & 7.50 & 6.07 & 6.65 & 8.33 & 10.00 & 3.33 & 2.50 & 6.04 & 6.36 & 5.00 & 7.50 & 3.75 & 5.65 \\
\hline Vrancea & 5.00 & 5.94 & 9.38 & 7.50 & 7.50 & 7.06 & 8.33 & 10.00 & 4.17 & 2.50 & 6.25 & 7.73 & 5.00 & 10.00 & 5.00 & 6.93 \\
\hline Mean & 3.44 & 7.10 & 9.00 & 6.85 & 6.33 & & 8.39 & 9.92 & 4.27 & 2.66 & & 6.90 & 7.50 & 6.95 & 5.55 & \\
\hline $\begin{array}{l}\text { Standard } \\
\text { deviation }\end{array}$ & 2.96 & 1.76 & 0.94 & 1.21 & 1.01 & & 0.29 & 0.44 & 1.79 & 0.61 & & 1.01 & 3.36 & 1.98 & 1.98 & \\
\hline
\end{tabular}


